Stoa

Vol. 12, no. 23, 2021, pp. 67-99

ISSN 2007-1868

\title{
METAFÍSICA ROSMINIANA
}

\section{Y “METAFÍSICAS” CONTEMPORÁNEAS"}

\author{
Samuele F. Tadini
}

RESUMEN: El ensayo busca evidenciar el objetivo de la metafísica rosminiana y la importancia de su configuración en el contexto de un diálogo crítico con algunas posiciones contemporáneas. El renacimiento del interés por el pensamiento metafísico en estos años y, también, la marginalidad a la que se ha relegado la Teosofia rosminiana, son los puntos fundamentales desde los cuales partir para proponer el discurso metafísico en el centro del debate internacional.

PALABRAS CLAVE: Rosmini · metafísica · teosofía $\cdot$ filosofía teorética $\cdot$ filosofía contemporánea.

ABSTRACT: The essay aims to highlight the scope of Rosminian metaphysics and the importance of its configuration in the context of a critical dialogue with some contemporary positions. The revival of interest in metaphysical thought of these years and, at the same time, the marginality to which Rosminian Theosophy has been relegated, are the fundamental points from which to start to bring Rosminian metaphysical discourse back to the center of the international debate.

KEYWORDS: Rosmini - metaphysics · theosophy $\cdot$ theoretical philosophy $\cdot$ contemorary philosophy.

\footnotetext{
* El texto original apareció en el volumen, cuidado por mí, La filosofia dopo le "filosofie". La sfida rosminiana alla contemporaneità, Mimesis, Milán-Udine 2019, pp. 99-129. Traducción de Jacob Buganza. 


\section{Perspectivas contemporáneas}

El debate metafísico contemporáneo, aun no desconociendo las perspectivas de estampa aristotélico-tomista o platónico-agustinianas de las llamadas metafísicas clásicas, nos pone frente a al menos cuatro posibles elecciones: la analítica (ciertamente la más difundida, no sólo en el mundo anglófono), la fenomenológica (más circunscrita), la hermenéutica (difundida sobre todo en el ámbito "continental") y la posmoderna (suficientemente difundida y extremadamente ambigua, en cuanto rechaza la metafísica sobre la base de una aserción "metafísica". ${ }^{1}$ La opción rosminiana, en cambio, que se configura como una Teosofía ${ }^{2}$, ha permanecido en los márgenes del debate contemporáneo por al menos tres razones de fondo, más allá de la pretendida "confesional", que la cualificaría como una "filosofía cristiana" (por lo cual, de por sí, se circunscribiría, según los detractores del pensamiento cristiano en general, a un área considerada marginal o descuidable); y la más banal, ligada a un simple "desconocimiento" de la obra rosminiana de parte de quien se ocupa de la metafísica en general.

Veámoslas anticipadamente.

1) La metafísica rosminiana expresa conceptos fuertes que necesitan, para poder ser adecuadamente afrontados, un no común "coraje metafísico", que contempla una comprensión fundamental de los resultados ofrecidos por las ciencias de intuición ${ }^{3}$ y de percepción ${ }^{4}$, antes de dirigir la mirada las ciencias de razonamiento ${ }^{5}$. Pero, preguntémonos, ¿cuántos metafísicos, o que se llaman tales hoy, estarían dispuestos a efectuar una misión de este tipo? Tomemos, por ejemplo, el término verdad ${ }^{6}$ en su esencialidad. Para Rosmini, la verdad, en tal

\footnotetext{
${ }^{1}$ Lyotard, por ejemplo, cuando describe el fin de las ideologías, reducidas a "metarrelatos", a la luz de una desconfianza en el progreso y el hombre, no hace otra cosa que elaborar una concepción de la realidad, a saber, una "metafísica" expresable con la afirmación de la constatación de la crisis de las certezas (J.-F. Lyotard, 1981)

${ }^{2}$ Cfr. S. F. Tadini y J. Buganza, La Teosofia de Rosmini, en preparación.

${ }^{3}$ Cfr. A. Rosmini, 1979, nn. 10-114, pp. 227-269 [hay traducción castellana: Sistema filosófico, edición de J. Buganza, Plaza y Valdés y Universidad Veracruzana, Madrid y México, 2010].

${ }^{4}$ Ibid., nn. 115-162, pp. 269-281.

${ }^{5}$ Ibid., nn. 163-263, pp. 281-302

${ }^{6}$ Rosmini 2005, n. 1114, p. 72. En el Nuevo ensayo explica que puede haber diversos usos para la palabra verdad, pero precisamente examinando los diversos significados que "se suelen atribuir, por el hablar común, al vocablo verdad, me parece que el más extenso significado para este vocablo, la noción general, la esencia única que propiamente significa, es la de ejemplar; y, por ende, he definido la verdad como el ejemplar de las cosas".
} 
acepción, es "la idea en cuanto es ejemplar de las cosas"7; ontológicamente hablando, "el objeto conocido por sí mismo. ${ }^{8}$ Esto demuestra que una adecuada comprensión del término no depende sólo del contexto específico de un sistema en el que viene explicitado, sino también del contexto más general de utilización: la verdad que viene a la luz por la lógica formal en relación a la corrección de una aserción, por ejemplo, no es necesariamente la misma verdad extraíble de una simple observación factual ${ }^{9}$; así también la verdad de los hechos no siempre responde a la verdad de las intenciones. ${ }^{10}$ Por esta razón, el término verdad, así como el término realidad, necesitan usarse rigurosamente y definirse semánticamente antes de elaborar cualquier teoría metafísica.

${ }^{7}$ A. Rosmini, n. 1118 , p. 75

${ }^{8}$ A. Rosmini 2011, n. 1021, p. 1072

${ }^{9}$ Tómese en consideración el siguiente silogismo curioso e impropio: (P1) Mi abuela tiene tres dientes ( $\mathrm{P} 2)$ El tenedor tiene tres dientes (C) Mi abuela es un tenedor. Más allá de que alguien podría objetar que la premisa mayor no es general, como cuando se afirma, por ejemplo, que "todos los hombres son mortales", sigue siendo verdad que ninguno podría objetar que (P1) no sea verdad, porque es factualmente verificable. Lo que formalmente puede ser corregido, empero, no significa que pueda ser verdadero en la realidad factual. El único modo para hacer aparecer como verdadera la asersión (C), a saber, la conclusión del silogismo, sería el declarar previamente que el término "abuela" y el término "tenedor" tengan el mismo significado, pero se trata de un presupuesto absolutamente arbitrario.

${ }^{10}$ Piénsese en el experimento que llamo "del bandolero". Tenemos que establecer la verdad procesual en relación a dos hechos aparentemente idénticos. Llamaré con A al primero y con B al segundo. Caso A: un bandolero entra en un banco con la pistola desenfundada y pide, con la amenza del arma, que se le dé el dinero. Caso B: otro bandolero se comporta del mismo modo. Frente a la verdad factual, podemos concluir estableciendo que ambos son culpables del mismo delito. La verdad factual en su conclusión lo confirma. Volvamos atrás y verifiquemos si el caso A y el caso B resultan iguales también en relación a la intencionalidad que ocasiona los hechos descritos. Imaginemos que la investigación policial haya descubierto que el bandolero del caso A hubiera premeditado todo, consciente y científicamente, sabiendo que el riesgo de delinquir era aceptable, dada la posibilidad de poder escapar, si lograba dar el golpe, con una considerable cantidad de dinero. Lamentablemente para él el arresto en fragancia ha elimiando su malvado sueño de riqueza. El bandolero del caso B, en cambio, no tenía en mente algo semejante. Por las investigaciones se descubre que un potencial asesino, que tenía como rehén a la esposa del presunto asaltante del caso B, había intimidado a este último para efectuar el atraco, con la amenza de asesinar a la esposa. En tal caso, no teniendo otra elección, el hombre se ha encontrado forzado a efectuar un atraco. Es evidente, en este sentido, que en el caso A hay una voluntad libre para delinquir, mientras que en el B la acción coercitiva ejercida por el potencial asesino ha terminado por obligar al marido de la rehén a efectuar un delito. Sobre la base de estos descubrimientos, ¿estamos seguros de que ambos casos deban ser tratados del mismo modo? La verdad factual efectiva es bien distinta de la verdad factual ocasionante: el bandolero del caso A era libre, mientras el "bandolero" del caso B estaba obligado. Esto demuestra, otra vez, que la explicitación de cualquier valoración, para poder ser correcta, en el sentido de una verdad incontrovertible, necesita de la mayor cantidad de elementos que sea posible, so pena de caer en el error. 
2) La metafísica rosminiana es una metafísica de la trascendencia, en la que el principio que defino onto-alético ${ }^{11}$ no puede ser rechazado si se pretende todavía elaborar una metafísica que tenga las características esenciales de performatividad, es decir, que no se limite a describir la realidad, sino que determina al hombre para penetrarla, para comprenderla y para que actúe moralmente según una coherencia incapaz de aceptar que la verdad sea simplemente una opinión o que tenga simplemente una validez lógico-formal.

3) La metafísica rosminiana expresa un sistema abierto a la verdad, mientras que hoy se tiende a excluir la posibilidad de la elaboración de un sistema y, en algunos ámbitos, no es raro que se termine por proponer el "no sistema" como sistema. Lo que resulta dominante en nuestra contemporaneidad, en todo caso, es la tendencia fragmentaria y fraccionista de las problemáticas, con el riesgo, bastante evidente, de la pérdida de vista de la finalidad unitaria garantizada por el sistema. Según David M. Armstrong, muerto hace poco y considerado uno de los mayores representantes del realismo australiano, resulta evidente que, aunque "la metafísica hoy [es] de nuevo respetable[...], es hoy practicada de modo fragmentario, y es difícil encontrar un acercamiento sistemático a la materia". ${ }^{12} \mathrm{Y}$, sin embargo, ésta es la situación hodierna y aquí es necesario retomar los movimientos si se quiere competir en el vasto y diversificado "mercado de las ideas", esto es, si se desea salir de la marginalidad.

\section{Cuestión de términos y significados}

Antes de afrontar la cuestión inherente a la metafísica rosminiana y a las "metafísicas" contemporáneas, sobre todo desde el punto de vista definitorio, sería necesario especificar por qué razón haya elegido poner el término "metafísicas" entre comillas. Es una cuestión básica y para nada secundaria, porque, en cuanto es verdad que la metafísica, en cuanto tal, permanece constantemente como una exigencia del hombre, más allá de la tentativa lanzada por

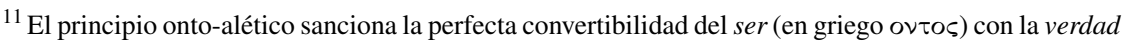
(en griego $\alpha \lambda \eta \vartheta \varepsilon\llcorner\alpha$ ). Escribe Rosmini: "preguntando qué cosa ES [la verdad], se viene a decir que cuando nosotros decimos que aquello que ella ES, se responde a la pregunta. Pero el ser es justamente lo que ES, y que es por esencia, porque es el ser. Si aquello que ES, ES aquello que ES, entonces aquello que ES es la verdad; por ende, el ser es la verdad" (A. Rosmini 1984, n. 1048, p. 442).

${ }^{12}$ D. A. Armstrong 2016, p. 25.
} 
algunos pensadores para quitarla de enmedio, no siempre las metafísicas propuestas por varios filósofos en el curso del tiempo han logrado ser tales, a saber, satisfacer, en cuanto es posible, las exigencias de una comprensión suficientemente adecuada de la realidad, o sea, de la totalidad, lo que significa una comprensión del ser tanto en su posibilidad como en su subsistencia finita e infinita. Aquí, empero, se coloca un prerrequisito fundamental de naturaleza terminológica que se refiere al modo de entender el término metafísica. Por esta razón, es necesario que comience a explicitar el significado; también porque, en nuestra contemporaneidad el término metafísica ha sufrido declinaciones tan diversificadas que vuelven extremadamente complejo el trabajo del historiador de la metafísica, sobre todo cuando está empeñado en la fase delicadísima de esta actividad específica, a saber, la reconstructiva. Algunas definiciones, en efecto, resultan particularmente interesantes y, en ciertos versos, también plausibles, sobre todo por la aplicación de la metafísica a otros ámbitos ${ }^{13}$, como la ciencia, la política, la sexualidad, el arte o la ética, para limitarnos a algunos ejemplos, sólo para subrayar la fundación metafísica necesaria a todo ámbito que desee se le reconozca su dignidad alético-valorativa. Esto no elimina, sin embargo, la pregunta inicial: ¿de qué tipo de metafísica se trata? Efectivamente, no hay que olvidar que, en nuestra contemporaneidad, el uso del término metafísica resulta a menudo expuesto a algunas curiosas, o

${ }^{13}$ Cfr. J. Evola, Metafisica del sesso, Edizioni Mediterranee, Roma 1993; W. Sombart, Metafisica del capitalismo, Edizioni di AR, Padua 19942; J. Ritter, Metafisica e politica, Marietti, Boloña 2000; J. Evola, Metafisica della guerra, Edizioni di AR, Padua 2001; G. Casalino, Il nome segreto di Roma. Metafisica della romanità, Edizioni Mediterranee, Roma 2003; T. I. Melendo Granados, Metafisica del concreto. I rapporti tra filosofia e vita, Leonardo da Vinci, Roma 2005; G. Giannini, Metafisica del conflitto, Il Nuovo Melangolo, Génova 2007; D. Callini, Arcani al lavoro. Metafisica della vita organizzativa, Franco Angeli, Milán 2008; D. Corradetti, Metafisica del numero. Vol. 1: Elementi di simbolismo matematico, Il Pavone, Messina 2008; E. Unger, Politica e metafisica. Tentativi filosofici in politica, Cronopio, Napoli 2008; A. Incampo, Metafisica del processo. Idee per una critica della ragione giuridica, Cacucci, Bari 2010; N. Zangwill, La metafisica della bellezza, Marinotti, Milán 2011; S. Givone, Metafisica della peste. Colpa e destino, Einaudi, Turín 2012; S. Ortoli - J.-P. Pharabod, Metafisica quantistica. I nuovi misteri dello spazio e del tempo, Castelvecchi, Roma 2013; S. Renik, Vedo cambiare il tempo. Metafisica del macchinismo e le passioni dell'anima, Mimesis, Milán-Udine 2015; M. Heim, Metafisica della realtà virtuale, Guida, Napoli 2015; A. Nothomb, Metafisica dei tubi, voland, Roma 2016; G. Bachelard, Metafisica della matematica, Castelvecchi, Roma 2016; G. Mina Di Sospiro, Metafisica del ping-pong. Un'introduzione alla filosofia perenne, Ponte alle Grazie, Milán 2016; E. Coccia, La vita delle piante. Metafisica della mescolanza, Il Mulino, Boloña 2018; G. Simmel, Metafisica della morte e altri scritti, SE, Milán 2018; F. Di Pace, Bambini e metafisica. Dio, il destino e Mandrake. Quando i piccoli ragionano dell'Assoluto, Fefè, Roma 2018. 
al menos temerarias, exageraciones ${ }^{14}$, que pueden resultar también suficientemente discutibles. ${ }^{15}$

Todo esto no debe sorprender. El lenguaje, como toda otra forma de elaboración humana, refleja siempre las más diversas estructuras conceptuales, ideológicas y sociales circunscritas al ámbito espacio-temporal en que se encuentran elaboradas por el hombre, tanto más cuando el individuo tiene la posibilidad de ejercer permeable y difusivamente este poder a través de los nuevos medios de comunicación. Un término recibido durante algún tiempo unívocamente, efectivamente, podría no mantener el mismo significado cuando su uso más común debiera emplearse en un contexto linguístico y social diversificado.

El término Idea ${ }^{16}$, por ejemplo, elevado por Platón al rango de forma ontológica, esencia substancial, esto es, ser (por esto es mejor escribirlo con mayúscula, para diferenciarlo del común ente de razón), ha sufrito notables modificaciones significativas; tan es así que, al menos desde Locke ${ }^{17}$, y por toda la tradición empirista-sensista después, salvo algunas excepciones ${ }^{18}$, al

${ }^{14}$ Cfr. S. Scansani 2007; M. Lenti 2012.

${ }^{15}$ Cfr. E. Abécassis 2004; L. De Sutter 2017; A. Carulli 2017; R. Rinaldi 2017.

${ }^{16}$ Baste considerar los caracteres metafísico-ontológicos de las Ideas individuados por Platón para darse cuenta: 1) Inteligibilidad: la Idea es apresable sólo por el intelecto ( $c f r$. PLATÓN, Fedone, en Tutti gli scritti, cit., 65 C-66 A, pp. 67-68); 2) Incorporeidad: la Idea pertenece a una dimensión metasensible (cfr. PLATÓN, Politico, en Tutti gli scritti, cit., 286 A, p. 344; Fedone, en Tutti gli scritti, cit., 85 E, p. 98; Filebo, en Tutti gli scritti, cit., 64 B, p. 473; Sofista, en Tutti gli scritti, cit., 246 B, p. 290 e 247 D, p. 291; Epinomide, en Tutti gli scritti, cit., 981 B, pp. 1776-1777); 3) Ser en sentido pleno: las Ideas son el ser que verdaderamente es ( $c f r$. PLATÓN, Repubblica, en Tutti gli scritti, cit., V, 477 A, p. 1209; V, 478 E-479 D, pp. 1211-1212; Sofista, en Tutti gli scritti, cit., 248 A-251 A, pp. 291-294; Fedro, en Tutti gli scritti, cit., 247 C-E, p. 556; Fedone, en Tutti gli scritti, cit., 75 C-D, p. 86; 78 D-79 A, p. 89); 4) Inmutabilidad: las Ideas no padecen alguna mutación o escapan al nacer y perecer (cfr. PLATÓN, Cratilo, en Tutti gli scritti, cit., 439 D-440 A, p. 182); 5) Perseidad: las Ideas son absolutamente objetivas, en cuanto son en sí y por sí (cfr. PLATÓN, Cratilo, en Tutti gli scritti, cit., 385 E- 386 E, pp. 136-137); 6) Unidad: las Ideas son, cada una, una unidad que unifica la multiplicidad de las cosas que participan de ellas (cfr. PLATÓN, Repubblica, en Tutti gli scritti, cit., V, 475 E-476 A, p. 1208; V, 479 A, p. 1211; VI, 484 B, p. 1213).

${ }^{17}$ Cfr. J. Locke 2012, p. 39.

${ }^{18}$ Piénsese, por ejemplo, en la recuperación hegeliana del término Idea (la Lógica estudia la Idea en sí, o sea, la Idea como se realiza en el ser, en el no ser y en el devenir, mientras el objeto de la Filosofía de la naturaleza es la alienación de la Idea por sí, por lo que la Naturaleza es la Idea fuera de sí. La Idea, empero, se actúa plenamente sólo cuando regresa en sí por la alienación de la Naturaleza, volviéndose Espíritu subjetivo, en cuanto se actúa en los individuos singulares, Espíritu objetivo, en cuanto se actúa en los diversos pueblos, y Espíritu absoluto, en cuanto se actúa en las grandes obras artísticas, religiosas y filosóficas, $c f r$. G. W. F. Hegel 1967; Scienza della logica, al cuidado de C. Cesa, 2 voll., Laterza, Roma-Bari 2008); también en el husserliano (Husserl reconoce que el ideal de la filosofía auténtica consiste en realizar la idea del conocimiento absoluto a partir de un fundamento cierto por medio del método fenomenológico. El análisis fenomenológico, poniendo 
término idea se le ha atribuido el significado de contenido de la mente y del pensamiento humano, en cuanto "objeto" del pensamiento de un sujeto: el hombre. Es en virtud de esta modificación del significado originario del término idea que hoy, en contextos cotidianos, nada filosóficos, nos resulta posible responder con la expresión "no tengo idea" a una hipotética pregunta que nos es planteada en relación a una particular situación de la que no tenemos conocimiento, y es siempre en virtud de esta misma modificación del significado originario que podemos exclamar " $i m e$ ha venido una idea!", cuando entendemos decir que hemos encontrado la solución a un problema. En el ámbito globalizado de nuestra contemporaneidad es fácil confundir una filosofía del todo, es decir, una filosofía de lo entero, con una filosofía de to$d o$, esto es, en la mejor de las hipótesis, una ontología de lo particular y, en la peor, una simple opinión expresada por quienquiera, tal vez mediante algún social network. Es claro, empero, que la opinión y la filosofía no son de hecho la misma $\operatorname{cosa}^{19}$, aun cuando la opinión propagada, incompetente y engañosa haya llegado a justificar tal impropio reduccionismo. ¿Qué decir, entonces, de otros términos ${ }^{20}$ ? Qué decir del término metafisica?

entre paréntesis el objeto natural en su singularidad, realiza aquella reducción eidética que conduce a las ideas, entendidas como esencias, que se revelan en la intuición inmediata de la conciencia, $C f r$. E. Husserl 1968; Idee per una fenomenologia pura e per una filosofia fenomenologica, al cuidado de V. Costa y E. Filippini, Einaudi, Turín 2002).

${ }^{19}$ Sobre este punto creo que tiene perfectamente razón Platón. Cfr. Platón 2000, V, 476 E-477 B, p. 1209; Menone, in Tutti gli scritti, cit., 97 C-98 B, pp. 963-964.

${ }^{20} \mathrm{Si}$ en el ámbito filosófico, empero, nos encontramos casi siempre frente a una forma explícita de variación terminológica, osaré decir declarativa, por medio de la cual el filósofo en turno nos informa preventivamente de qué modo debemos entender un determinado término en el ámbito específico de su discurso, cuando nos movemos fuera de este contexto descubrimos que las razones de cambio o sustitución de significado de un término no obedecen a la exigencia de una lógica revelativa, dirigida a obtener una siempre más refinada clarificación terminológica preventiva; a veces, al contrario, las susodichas razones están destinadas a generar una alteración de significado o, incluso, una verdadera y propia eliminación de un particular término tout court por otras finalidades, a menudo ocultas. Todo esto se da para satisfacer una exigencia generalmente impuesta "desde lo alto", como está sucediendo hoy con el término confesionario y el término inmigrado. La definición del término confesionario dada por el diccionario es la siguiente: "Sede en la cual el sacerdote confesor administra el sacramento de la penitencia: consiste generalmente en un sitio de madera, a menudo ricamente adornado, con un asiento para el confesor y dos reclinatorios laterales para los fieles, separados por el asiento mediante una pared divisoria interrumpida por una pequeña grada" (Vocabolario della lingua italiana, 5 voll. [1986-1994], Istituto della Enciclopedia Italiana, Roma 1986, vol. I, p. 888). El significado es claro: es un lugar específico en donde el sacerdote recibe la confesión del fiel para administrar el sacramento de la confesión. Se trata de un lugar íntimo, reservado, serio y privado. En la acepción difundida por los reality shows como el Gran hermano, el término confesionario ha asumido el significado diametralmente opuesto al originario: es un lugar en que uno o más participantes se desahogan frente a un público diversificado, constituido por simples curiosos, fanáticos y líderes de opinión de todo tipo. Se nos podría cuestionar: ¿por qué ha sido necesario mutar un término que tiene una connotación tan es- 
La problemática metafísica contemporánea parece colocarse entre dos antitéticas perspectivas: por un lado, la inaugurada por Nietzsche y, por otra, la inaugurada por Wittgenstein. Con la primera se afirma que no existen hechos, sino sólo interpretaciones ${ }^{21}$, con la segunda se afirma que "el mundo es la to-

pecífica en el lenguaje religioso y proponerlo con un significado contrario? ¿No habría sido oportuno, por razones de claridad y respeto, utilizar otro término más en consonancia? Más allá de cualquier polémica, no es posible excluir la duda de que se haya dado intencionalmente y no "al azar". Pero aquí nos encontramos frente a un caso de transformación de significado, mientras que en el caso del término inmigrado tenemos que vérnosla con un caso de supresión terminológica. El término inmigrado, casi siempre asociado a otros dos términos, regular (connotación positiva) e irregular o clandestino (connotación negativa), ha sido prácticamente eliminado de los media (impresos o por televisión) y sustituido por el término migrante, en virtud del hecho de que parecería resultar menos agresivo desde un punto definitorio, o sea, más neutro. Es preciso señalar, empero, que hay una clara diferencia, al menos en la lengua italiana, entre inmigrado, emigrante y migrante. En el diccionaro se lee para la voz inmigrado la siguiente definición: "Que, o quien, se ha transferido a otro país: trabajadores inmigrados, familias inmigradas en el Norte; en sentido específico, refiriéndose a cambios de lugar determinados por los desniveles en las condiciones económicas de varios países; quien se ha establecido temporal o definitivamente por razones de trabajo en un territorio diverso del de origen" (Vocabolario della lingua italiana, 5 voll. [1986-1994], Istituto della Enciclopedia Italiana, Roma 1987, vol. II, p. 768). Para el término emigrante se lee la siguiente: "Quien emigra, en particular, quien expatria, terminal o definitivamente, por razones de trabajo" (Vocabolario della lingua italiana, 5 voll. [1986-1994], Istituto della Enciclopedia Italiana, Roma 1987, vol. II, p. 252). Para el término migrante, en fin, cuanto sigue: "1. Que migra, que se mueve o cambia de sede: pueblos, animales, párajos migrantes. 2. Con significado más técnico, en biología o medicina, de célula u órgano que tiene capacidad o posibilidad para cambiarse - activo o pasivo, de acuerdo con el caso — de la sede habitual, por causas varias. En particular: células migrantes (o células migratorias o macrófagas), de naturaleza retículo-endotelial, que tienen notable importancia. En los fenómenos inflamatorios; reumas migrantes, reuma que se ha movido de su sede normal por alteración del lugar que lo contiene. Analogam, absceso m., absceso frío que de la primitiva sede de formación se cambia bajo la influencia de la gravedad, siguiendo las vías de menor resistencia (espacios celulares o perivasculares)" (Vocabolario della lingua italiana, 5 voll., Istituto della Enciclopedia Italiana, Roma 1989, vol. III, p. 221). Podemos preguntarnos: ¿por qué ha sido necesario eliminar un término extremadamente claro que contempla una definición objetiva, es decir, tanto positiva (regular) como negativa (irregular), del significado de inmigrado y que corresponde a la realidad de los hechos? ¿Es más justo contemplar, en la efectiva posibilidad, que todos los inmigrados que se cambian de un lugar a otro lo hagan exclusivamente por cuestiones de trabajo, políticas o ideológicas, o es más probable que haya también algunos —no importa si pocos o muchos - que persiguen, a dondequiera que vayan, actividades criminales de todo tipo? Por razones de cientificidad, no es posible excluir ni la primera ni la segunda hipótesis, porque ambas se soportan con ejemplos que muestran la acción valiosa de tantas buenas personas y la acción de iguales criminales. Frente a una hipotética pregunta sobre la presencia o menos de una bien estructurada lógica detrás de esto, tendría dificultad por responder negativamente, liquidando todo diciendo que se trata de un simple "caso". ¡Lo cierto es que no se puede sostener imposible lo posible!

${ }^{21}$ Sostener, siguiendo a Nietzsche, que "no hay hechos, sólo interpretaciones" (F. Nietzsche 1990, 7, p. 60) es una toma de posición problemática. Me pregunto: ¿por qué quienes sostienen tal aserción, tal vez frente a un padre que ha perdido un hijo, no le dicen: "no se preocupe, no hay hechos, sólo interpretaciones"? Tal vez porque la reacción, más que jusitificada, sería violenta. Encontrarse tirado con la nariz rota sería la más evidente demostración de que el mundo no es una fábula, que los hechos son hechos y que una de las tantas interpretaciones posibles en respuesta a la susodicha afirmación no ha sido una palabra, sino un gesto, una acción real, o sea, un hecho en respuesta a una interpretación. En 
talidad de los hechos, no de las cosas". ${ }^{22}$ Frente a estas dos perspectivas, ¿qué tipo de metafísica se podrá elaborar?

Para evitar una elección inicial de campo, tomaré el término metafísica en una acepción muy general, a saber, no todavía cualificable como idealista (reducción del ser al pensamiento, negación de la existencia autónoma de la realidad, en cuanto reflejo de una específica actividad íntima al sujeto mismo pensante) o realista (afirmación de la existencia de una realidad independiente del pensamiento). Para satisfacer este requisito, atribuyo al término metafísica el significado de "concepción de la realidad expresada racionalmente por el hombre". El hecho de que sea la expresión racional de un sujeto pensante que defino hombre, sostengo que es aceptable sobre la base del sentido común, dado que no resulta actualmente posible establecer si hay elaboraciones metafísicas diversas de las que genera el ser humano. Es a la luz de tal esclarecimiento que es posible resolver la cuestión inicial.

Si concentramos nuestra visión sobre las filosofías contemporáneas, desde 1900 en adelante, es posible constatar que ellas expresan diversas concepciones de porciones de la realidad (lógica, física, ética, política, economía, psicología, artística, etcétera), de la que enseguida efectúan diversas interpretaciones, pero no llegan a dotar de soluciones válidas referentes a los problemas que se encuentran en la realidad considerada como lo entero. Aun en la positividad de una pluralidad de concepciones de la realidad, incluso fragmentaria, dirigida a expresar su sentido, el valor, la esencia y la modalidad, es necesario señalar que, más allá de las diferentes metologías, muchas de estas "metafísicas" parecen orientadas a desestimar al menos dos elementos clave, osaré decir estructurales, de la metafísica misma: el sistema y la trascendencia.

tal sentido, un padre podría decir, luego de haber golpeado al susodicho provocador, "no se preocupe, el dolor que siente no es un hecho, sólo una interpretación".

${ }^{22}$ L. Wittgenstein 1998, 1.1, p. 25. Preguntémonos: un hecho es tal, ¿independientemente de la interpretación que se puede dar de él? El hecho de que yo sueñe algo que en la realidad no existe, ¿es siempre un hecho? ¿Un hecho puede ser considerado desde diversas perspectivas? ¿Un hecho es por sí unívoco en su singularidad? Etcétera. Resulta claro que preguntas de este tipo, y otras todavía que se pueden agregar, revelan una problematicidad que se radica en la necesidad por definir qué cosa es un hecho, dado que Wittgenstein niega que los hechos se reduzcan a cosas. 
El sistema ${ }^{23}$ es importante por al menos dos razones: además de asegurar el desarrollo lógico y racional del discurso metafísico, es determinante precisamente en la explicitación coherente de una concepción completiva de la realidad, que de otro modo resultaría difícilmente comunicable, incluso porque la fragmentariedad, de la que se puede aceptar el acercamiento pluralista inicial, permanece inexplicable si no es reconducida sistemáticamente a la unidad. No hay que olvidar, sin embargo, que al término de la segunda Guerra Mundial decir "sistema" parecía expresar una forma de "pensamiento único"; legado de un horror vivido poco tiempo antes a causa de los experimentos totalitarios. En todo esto, más allá del error de entender el término "sistema" ex-

${ }^{23}$ Los paradigmas metafísicos post-hegelianos tienden a ser casi siempre asistemáticos, en el sentido de que rechazan la tentación de elaborar un sistema que pretenda expresar, de modo completo, una determinada concepción de la realidad. Se fraccionan y sus cultivadores se ocupan de problemas específicos, por lo que resultan, en la mejor de las hipótesis, descripciones parciales de una porción o fracción de la realidad. El rechazo de un determinado sistema, empero, no es una cosa nueva en el ámbito filosófico; es nuevo, sin embargo, el rechazo al sistema en cuanto tal, porque ya en la Antigüedad las filosofías de la edad helenística se habían opuesto a las grandes construcciones metafísicas de Platón y Aristóteles, pero su oposición había contribuido a crear paradigmas ontológicos y cosmológicos que buscaban, comoquiera, ser completos, sustituyendo a un sistema metafísico de la trascendencia por uno de la inmanencia. En la Edad moderna, sobre todo como reacción a los paradigmas racionalistas de Descartes, Malebranche, Spinoza, Leibniz y Wolff, el empirismo de Locke y, sobre todo, el sensismo de Hume han contribuido a generar un cambio de dirección teorética que ha contribuido al desarrollo del criticismo de Kant, el cual se preguntaba si era posible todavía una metafísica como ciencia. El punto nodal está en el término como. Porque la pretensión por elevar a rango de ciencia a la metafísica terminaba por reducir la metafísica a las ciencias, ahí donde entre metafísica y ciencia mantienen diferencias substanciales: el objeto de la metafísica es el ser en su totalidad, mientras la ciencia, empeñada por descubrir las leyes que regulan los fenómenos, se ocupa de aquella porción de realidad observable empíricamente por medio de una metodología que podríamos definir hipotético-deductiva. El prejuicio ligado a una concepción según la cual la metafísica se encontraría en un status pre-científico, es todavía actual. Strawson, por ejemplo, sostiene que "lo que inicia como metafísica puede terminar como ciencia" (P. F. Strawson 1967, p. 118). Del criticismo kantiano brotaron, variopintamente, los diversos tipos de idealismo y, si no juzgamos excesivamente temeraria la posición de Stirling (Cfr. J. H. Stirling 1865), podremos incluso afirmar que sin Kant la filosofía hegeliana no había sido la misma. Después de la temporada hegeliana y las reacciones críticas de Schopenhauer, Feuerbach, Marx y Kierkegaard, para limitarnos a algunos ejemplos, se asistió al desarrollo de la corriente positivista y de todas aquellas filosofías que, de varias maneras, sintieron la exigencia por "superar" la filosofía hegeliana, generalmente individuada como la última gran expresión sistemática de un paradigma metafísico juzgado ya inadecuado. La reacción a estas posiciones cientificistas se tuvo con una reafirmación del neoidealismo, del trascendentalismo, del existencialismo y de todas las varias formas de espiritualismo que subsiguieron: todas estas experiencias teoréticas fueron el resultado de un modo diverso de observar al mundo, un mundo ya no expresable o comprensible a la luz de las conclusiones a las que habían llegado las filosofías sistemáticas recientes. El sistema, en cuanto tal, entendido como la expresión de una visión unitaria y estática de la realidad, se consideraba negativo a causa de su propia posición como elemento coercitivo, apto para embridar la libertad de toda conciencia. Para una visión de conjunto muy bien articulada y documentada sobre los diversos paradigmas metafísicos surgidos en el ámbito de la filosofía occidental, cfr. B. Mondin 1998. 
clusivamente en dicho sentido, es decir, como la expresión de una metafísica cerrada en sí misma y muy peligrosa, hay un elemento de verdad secundario: se comenzaba a comprender, gracias al análisis, que no podría haber proyecto antropológico, ético, político y económico sin una previa concepción de la realidad desde la cual partir para volver una idea performativa sobre el plano de la realidad contingente e inmanente en la que el ser humano se encontraba viviendo y obrando. Tras las grandes ideologías que han condicionado brutalmente la historia del 1900, piénsese en el comunismo y el nazismo, habían obrado "metafísicas" inmanentistas (es decir, cerradas en el horizonte limitado y limitante de la inmanencia) extraordinariamente fuertes y dinámicas, sin las cuales el sistema estatolátrico y totalitario no habría siqueira podido configurarse como tal.

Hoy, proyectados indefiniblemente hacia un futuro incierto y pluralísticamente diversificado, pero monolíticamente impuesto por lógicas siempre más explícitas, se asiste a la paradoja del "no-sistema" como sistema alternativo y del "no-pensamiento" como pensamiento alternativo: a una visión unitaria se le ha sustituido por una visión fragmentaria, blanda; a un pensamiento crítico se le ha sustituido con la opinión, a menudo condicionada por el fenómeno de los fake news. Después de todo, ha sido suficiente negar que existiese una verdad objetiva, frente a muchas verdades subjetivas, para detonar la bomba del relativismo y hacer creer a muchas personas, por ejemplo, que la democracia, como se le entiende hoy, es una respuesta tranquilizadora para el hombre posmoderno. Ciertamente, el relativismo no es propiamente un "sistema", pero sus asunciones, si se consideran bien, son suficientes para generar un paradigma metafísico inmanente, o sea, para desarrollar una concepción de la realidad de lo finito fundada sobre la opinabilidad de todo valor: del nihilismo se ha pasado a una posmodernidad ablandada y conciliadora, no preparada para afrontar los desafíos del presente ya a partir del significado forzadamente endulzado utilizado para expresar ciertos términos, o forzadamente equiparacionista, sobre todo cuando se trata de temas que tienen que ver con la moral, la religión y la política. A nivel genuinamente lingüístico, en fin, no se debe olvidar el ahora autorizado hábito del hablar soez incluso a nivel literario; sin embargo, líos para quien utilice un término cónsone para definir a alguien que, además de comportarse como idiota, lo es. ${ }^{24}$

\footnotetext{
${ }^{24}$ Permítaseme lo siguiente: si hoy Rosmini hubiera querido publicar la traducción italiana del $D e$ catechizandis rudibus de san Agustín, ningún editor le habría permitido publicarlo con el título por él propuesto: Del modo di catechizzare gli idioti (Giuseppe Battaggia, Venecia 1821). Esto porque, si hoy
} 
Vayamos ahora al segundo término. La trascendencia no debe entenderse como una suerte de Deux ex machina para jalar de él toda vez que nos encontremos en un impasse: la trascendencia es un horizonte teorético plausible, es decir, posible, cuya negación deja sin resolver muchas aporías. El problema de la trascendencia, además, está estrechamente ligado a la posibilidad misma por elaborar una teología natural coherente, pero en algunas filosofías ha terminado por ser considerado como un pseudo-problema, como algo irresoluble o que hay que negar bellamente, a la luz de una pretendida imposibilidad por andar más allá de la inmanencia de lo conocido. La teología natural, que históricamente constituye una parte esencial de la metafísica, ha terminado por derruirse también ella bajo los golpes de los martillos cientificistas y materialistas que, en los dos siglos anteriores, han animado algunas triunfales concepciones filosóficas.

Como he puesto de manifiesto en otra parte ${ }^{25}$, es posible individuar las etapas decisivas de este desmoronamiento que, si es verdad que han conducido a la formulación de la categoría teorética de la posmodernidad, también han mostrado la inconsistencia duradera de algunas posiciones teoréticas que se han demostrado absolutamente insatisfactorias para resolver los problemas dejados inevitablemente abiertos por todas aquellas concepciones de la realidad que han negado, más o menos explícitamente, la posibilidad misma de una apertura a la trascendencia, o sea, a la posibilidad misma de una metafísica de la trascendencia. Por esta razón, el renacimiento de las "metafísicas" contemporáneas, aun cuando son lejanas de la idea de una elaboración sistemática completiva, tienden a reproponerse y a suscitar notable interés, incluso cuando, en la mayor parte de los casos, resienten pesadamente tradiciones que parecen forzarlas a la elaboración de ontologías reduccionistas.

es posible dar espacio a toda forma de vulgaridad lingüística o textual (cfr. A. Busi 2002; R. I. Sutton 2007; I. Bahr 2007; A. L. Antunes 2014), no parece igualmente posible decir las cosas como son, utilizando un término (idiotas) que podría ser juzgado ofensivo por alguien, mientras otras palabras, que ahora son parte del uso común, por muchos son consideradas prácticamente inofensivas, pero, incluso, más comprensibles para la mayoría (¡bella tiranía de la mayoría!). Pero, preguntémonos, ¿quiénes son los idiotas, sino personas toscas y carentes de instrucción que, en virtud de su ignorancia, se erigen como jueces de todo y todos y no parecen apresar la diferencia entre el hablar soez y el hablar normal? Ciertamente, el término idiota significa "persona de escaso entendimiento, estúpido, deficiente" (Istituto della Enciclopedia Italiana 1987, p. 735) y, precisamente en virtud de esta acepción, el susodicho volumen rosminiano podría ser rechazado, mientras que, en realidad, sería perfectamente útil para evitar a muchos permanecer en la idiotez, o sea, en un estado de "estupidez, inteligencia carente" (Istituto della Enciclopedia Italiana 1987, p. 735) y presunción.

${ }^{25}$ Cfr. S. F. Tadini 2015, pp. 22-24. 


\section{Metafísicas propias y metafísicas impropias}

Muchos historiadores de la metafísica han presentado diversos modelos definitorios aptos para distinguir las variadas concepciones de la realidad, expresadas en el curso del tiempo, con base en características determinantes. Piénsese en Étienne Gilson ${ }^{26}$, que ha propuesto distinguir las metafísicas esencialistas de las existencialistas, para mostrar la superioridad de la metafísica tomista respecto a todas las otras, o bien la de Enrico Berti ${ }^{27}$, que ha preferido distinguir las metafísicas trascendentalistas de las inmanentistas, para mostrar la legitimidad de la metafísica en cuanto tal.

Personalmente prefiero distinguir las metafísicas propias de las impropias, entendiento por propias sólo las metafísicas de la trascendencia, porque son las únicas que dejan abierta la posibilidad de lo otro que está más allá de lo empírico (lo metaempírico) y no tienen el riesgo de auto-confinarse al interior de un ámbito preestablecido, sea la materia, el lenguaje, la praxis, la historia o la nada. Las metafísicas propias de la trascendencia, a mi parecer, pueden lanzarse más allá de la platónica segunda navegación ${ }^{28}$ cuando emprenden una tercera navegación, lo cual es posible sólo en un cierto contexto cristiano, en cuanto reconoce el hecho de que la metafísica, aun siendo la ciencia que más allá de todas lleva al hombre a los confines de sus posibilidades racionales, no puede garantizar salvación alguna. Podrá mostrar los principios fundamentales, pero para atravesar el mar del tiempo y alcanzar la salvación, como ha explicado san Agustín, no sirve una teoría, sino un lignum crucis, porque "Es como si alguien divisara desde lejos su patria, pero un mar se interpusiera entre los dos: ve a dónde ir, pero ignora el camino. Así nos ocurre a nosotros: anhelamos alcanzar nuestra condición estable, donde el ser realmente es, porque seguirá siendo siempre lo que es; pero está por medio el mar de este mundo, por donde caminamos, aunque ya vemos a dónde caminamos. $\mathrm{Mu}$ chos ni siquiera saben a dónde van. Pero para enseñarnos el camino, vino el mismo a quien queríamos ir. ¿Y qué hizo? Nos puso el leño con el que poder atravesar el mar. Nadie es capaz de pasar el mar de este mundo si no lo lleva la cruz de Cristo. A veces abraza al árbol de la cruz incluso el de ojos enfermos. Y quien de lejos no ve a dónde va, no se aparte de ella, y ella misma lo llevará". 29

\footnotetext{
${ }^{26}$ Cfr. E. Gilson 1952, pp. 154-215.

${ }^{27}$ Cfr. E. Berti 2017, pp. 14-28.

${ }^{28}$ Cfr. Platón cit., 99 B-102 A, pp. 107-109.

${ }^{29}$ Agustín, Comentario al Evangelio de Juan, 2, 2.
} 
Las metafísicas impropias, en cambio, son tales en la medida en que resultan ser pseudo-visiones de la realidad o parciales visiones de la realidad, o sea, que no tienen en cuenta "toda" la realidad, lo entero, y pueden ser tales incluso cuando se evidencian como anti-metafísicas. Esto puede suceder a causa de un exasperado reduccionismo cientificista ${ }^{30}$ (piénsese en las asunciones propuestas por el Círculo de Viena ${ }^{31}$ ), pero también a causa de una excesiva desvaloración en la posibilidad racional del hombre (piénsese en el pensamiento débil ${ }^{32}$ ). Todas las visiones explícitamente materialistas, según las cuales es verdad, válido y real sólo lo que es concreto, tangible, racionalizable y definible al interior de un contexto típicamente concluido en el ámbito material, terminan por dar, a lo mucho, una ontología material, pero no llegan a elaborar una metafísica propia, porque la concepción de la realidad que vendría a configurarse, en coherencia con las premisas ontológicas asumidas, no puede más que mostrar una realidad confinada subjetiva y arbitrariamente a la sola materialidad. Se podría preguntar: ¿es más científica la postura teorética de quien — por varias razones - opta por una exclusión apriorística de lo que no se encontraría en el ámbito material, o bien la de aquél que, apriorísticamente, no excluye ninguna?

En razón de esta duda es fácil responder que todas las concepciones de la realidad presentadas como cerradas en sí mismas y no dispuestas a admi-

\footnotetext{
${ }^{30}$ También las filosofías explícitamente anti-metafísicas son "metafísicas" (impropias), porque necesitan comoquiera una referencia fundamental a un principio, que de por sí —les guste o no- es ya una proposición metafísica ( $c f r$. J. O. Urmson 1974, pp. 126-140). Creo que Joad tiene razón cuando afirma, contra las pretensiones anti-metafísicas de los neopositivistas que se decantaban por el principio de verificación, que "el principio de verificación es una proposición metafísica y, por ende, si se debe creer al positivismo lógico, carente de sentido" (C. E. M. Joad 1951, p. 71). Resulta claro que, en virtud de la pretendida coherencia al principio formulado, los mismos cultivadores del neopositivismo, que colocaban la propia "fe" cientificista en el principio de verificación, deberían concluir que tanto el neopositivismo, como el principio en el que se funda, son ambos carentes de sentido. Sobre este punto está de acuerdo también Wisdom, el cual se pregunta qué cosa significa aceptar el principio de verificación: "¿Qué es aceptarlo? Cuando algunas personas pronuncian de modo atrevido las palabras "el significado de una aserción es el método de su verificación", como uno que diga "el valor de una cosa en realidad es dado simplemente por su valor de cambio", ¿de qué modo están usando las palabras? ¿Cuál es la naturaleza general de su teoría? La respuesta es "es una teoría metafísica”", J. Wisdom 1938, 47, p. 454.

${ }^{31}$ Las posiciones de Carnap (R. Carnap 1969, pp. 504-532), del Círculo de Viena en general, y del llamado "primer Wittgenstein" en el Tractatus Logico-Philosophicus, fuertemente influencia por el criterio de significación ofrecido por el principio de verificación, eran totalmente antimetafísicas. Estos filósofos, y quienes han seguido esta línea, llegaron a definir los problemas de la metafísica como estados patológicos mentales; así que la misma validez de la filosofía podía establecerse sobre la base de la acción terapéutica aplicada a la superación de los "pseudo problemas metafísicos".

${ }^{32}$ Cfr. AA. VV. 2010
} 
tir que pueda haber algo más, es decir, algo que esté más allá y que pueda dar razón de la inmanencia, terminan por configurarse como ontologías de lo "finito". Tales elaboraciones pueden alcanzar un extraordinario nivel de profundidad argumentativa y una termonología-analítica refinada, pero de hecho no cumplen el paso esencial que les permitiría emprender la platónica "segunda navegación", a saber, fuera de la metáfora, realizar una metafísica propia. Por esta razón, sostengo que es cuanto menos exigencial, a nivel formal y metodológico, distinguir las metafísicas impropias de las propias, o sea, distinguir aquellas concepciones de la realidad que se cierran en sí mismas de las que se demuestran abiertas a la verdad. Se comprende, entonces, que poner entre comillas el término "metafísica" respecto al uso del mismo término sin comillas corresponde a una exigencia clarificadora que pretende sólo evitar una posibile ambigüedad. Esto significa que todas las filosofías expresan una ontología ${ }^{33}$, esto es, una concepción del ser, pero no todas llegan a elaborar una metafísica propia, o sea, una coherentemente legítima. ${ }^{34}$

A menudo presupuestos errados y preconceptos igualmente engañosos han contrubuido a generar "metafísicas" ilegítimas, pero también en el ámito de las metafísicas legítimas se pueden encontrar defectos y problemáticas que necesitan continuos repensamientos, profundizaciones y clarificaciones, por lo que, frente a la pregunda de si es posible progresar en metafísica considero se puede responder afirmativamente. Obviamente no existe una metafísica perfecta y definitiva, porque, aun cuando sea refinada y genial, es siempre producto de una mente finita; pero puede haber metafísicas más o menos dispuestas en apertura a la verdad, y son éstas las que, tal vez más que todas las otras, merecen ser estudiadas sin demora alguna: ¿qué mérito tendría un metafísico de hoy si no contribuyese a mejorar la comprensión que el hombre tiene de la realidad, de toda la realidad?

\footnotetext{
${ }^{33}$ Cfr. AA. VV. 2008.

${ }^{34}$ Alguien podría objetar que el término legítimo, aplicable a la valoración de una metafísica propia, pueda ser excesivamente fuerte e, incluso, subjetivo, en el sentido de que responde a una exigencia estrechamente personal de quien comparte más o menos esta perspectiva, pero, en realidad, la legitimidad o ilegitimidad de una metafísica se valora con base en los problemas que resuelve y que deja sin resolver, y las llamadas "metafísicas" impropias resultan ilegítimas por la extraordinaria cantidad de problemas que no están en grado de resolver completamente.
} 


\section{La perspectiva metafísica rosminiana y las "metafísicas" contemporáneas}

Quien ha creído que después de las críticas del neopositivismo y de todas las filosofías de la inmanencia y la posmodernidad no sería posible elaborar una metafísica, no sólo ha extraviado el sentido más auténtico de la filosofía, que para Rosmini es esencialmente la "ciencia de las razones últimas" 35 , sino que ha expresado dogmáticamente una posición hoy no considerada válida. Si es verdad que la respuesta a la pregunta sobre el ser parecía casi limitarse a la paradójica descripción de una realidad incomprensible, en la cual el hombre, esto es, aquel mismo individuo que Sartre ha descrito como "una pasión inútil" ${ }^{36}$, cuando buscase alcanzar la verdad del ser, no podría hacer más que aceptar que se encuentra frente a su manifestación en la historia, es igualmente verdad que, en el ámbito de otras orientaciones de pensamiento, se ha registrado un regreso a la metafísica. Varzi ha puesto de relieve que, en el ámbito analítico, "después del giro linguístico de principios de 1900 y el giro cognitivo de los últimos decenios, el nuevo siglo parecer haber arrancado con la insignia de una enfática y, en ciertos casos, inesperado giro metafísico" ${ }^{~}{ }^{\text {, }}$ mientras Micheletti ${ }^{38}$ ha subrayado la exigencia de algunos filósofos analíticos por emprender lo que podría ser definido incluso como "giro religioso" de la analítica contemporánea. La analítica desarrollada a partir de los resultados del llamado "segundo Wittgenstein", en efecto, ha conducido a algunos filósofos que se han reconocido en esta dirección metodológica de pensamiento a considerar válida la posibilidad de una nueva indagación ontológica, que ha permitido elaborar una nueva teología natural ${ }^{39}$, la cual, como he documentado en otro sitio $^{40}$, podría ponerse en diálogo constructivo con la rosminiana.

Tomemos en consideración las diversas perspectivas contemporáneas que he indicado al inicio y pongámoslas frente a la teoresis rosminiana, que es

\footnotetext{
${ }^{35}$ Para comprender qué entiende Rosmini por metafísica, es preciso, antes que nada, individuar lo que entiende por filosofía, porque la metafísica es la parte esencial de toda filosofía que pretenda ser una "ciencia de las razones últimas" (A. Rosmini 1988, n. 13, p. 24). Pero, ¿qué cosa son las "razones últimas" de las que habla Rosmini? Son las "respuestas satisfactorias que el hombre da a los últimos por qué, con los cuales su mente se interroga a sí misma" (A. Rosmini 1979, n. 2, p. 225). Rosmini entiende por metafísica "la doctrina filosófica del ente real y completo", o sea, "la doctrina de las razones últimas del ente real" (A. Rosmini 1988, n. 11, p. 23).

${ }^{36}$ J.-P. Sarte 2014, p. 697.

${ }^{37}$ A. Varzi 2008, p. V.

${ }^{38}$ Cfr. M. Micheletti 2002.

${ }^{39}$ Cfr. M. Damonte 2011; ID. 2011, f. I, pp. 11-28; ID., AA. VV. 2018, pp. 245-276.

${ }^{40} C f r$. S. F. Tadini en AA. VV. 2017, pp. 65-107.
} 
la expresión de un sistema completo. Lo que se podrá observar, como punto de encuentro formidable, es la atención en el uso del lenguaje, la corrección terminológica preeliminar: lo que Rosmini tiene en común con los filósofos contemporáneos es la exigencia de una previa semántica lexical.

El interés de los filósofos analíticos casi siempre se circunscribe a especificar temáticas metafísicas ${ }^{41}$ (existencia, identidad, persistencia, modalidad, propiedad, causalidad, etcétera), expuestas lógicamente, pero sus intentos son lejanos a la elaboración de un sistema. Putnam, por ejemplo, refiriéndose a una recolección de sus escritos, no ha dejado de afirmar cuanto sigue: "no he buscado proponer una concepción global de la naturaleza de la filosofía, y aunque quisiera hacerlo, no tengo ninguna concepción global qué proponer". ${ }^{42}$

También los fenomenólogos, aun interesados en varias cuestiones metafísicas, rehuyen al sistema. Ellos, hoy más que nunca, pretenden "luchar contra la fetichización del saber científico"43, aún en las diversas articulaciones del desarrollo del método fenomenológico en direcciones incluso distantes de las proyectadas por Husserl, pero parecen aceptar una posición basilar, explicitada por su maestro en las Meditaciones cartesianas, de acuerdo con la cual la exclusión de la "metafísica ingenua" que tiene que ver con las cosas en sí, "no excluye, en general, una metafísica" ${ }^{44}$ La fenomenología, en efecto, no es una ciencia de hechos, sino de esencias, cuyo objetivo es describir los modos típicos con los que los diversos fenómenos se presentan a la conciencia, la cual siempre es conciencia de algo. La intencionalidad de la conciencia, empero, deja abierta la cuestión acerca de la opción realista o idealista: cuando se afirma que la conciencia es siempre conciencia de algo, significa que la conciencia se refiere $a$ otro, pero esto otro, ¿estamos seguros de que existe efectivamente fuera de la conciencia? Los fenomenólogos, además, cuando se ocupan de ontología material ${ }^{45}$, pretenden explorar y describir la natura-

${ }^{41}$ Cfr. AA. VV. 2008.

${ }^{42}$ H. Putnam $2004^{3}$, p. 21.

${ }^{43}$ G. Fornero - S. Tassinari 2002, vol. I, p. 607.

${ }^{44}$ E. Husserl 1970, p. 174.

${ }^{45}$ Husserl distingue la ontología en formal y material (cfr. E. Husserl 1968). La ontología formal tiene por objeto al ente en general y se dirige al estudio de las estructuras últimas de las que la realidad resulta necesariamente organizada; se identifica con la lógica. Según Husserl, a la ontología formal conciernen los juicios analíticos a priori. La ontología material, en cambio, ocupándose de los diversos aspectos específicos de la realidad, se explicita en diversas ontologías materiales, cada una de las cuales se configura como el estudio aplicado a un sector o, si se prefiere, a un aspecto específico de la realidad. Según Husserl, la ontología material se referiría a los juicios sintéticos a priori. En tal 
leza, la sociedad, la moral y la religión, buscando apresar las modalidades típicas (esencias) con las cuales los fenómenos naturales, sociales, morales, religiosos, etcétera, aparecen a la conciencia. Su reflexión alcanza a elaborar ontologías regionales, pero no un sistema.

También la hermenéutica, después del cumplimiento gadameriano del paso de las hermenéuticas regionales a la hermenéutica general, se ha configurado como problema ontológico, aun en diferentes formulaciones, entre las cuales la de Ricoeur merecería un discurso a parte. Escribe con claridad Fornero: "si el hombre es un animal interpretante, lo es tanto más cuanto su experiencia de la realidad se vuelve problemática y compleja, por lo que parece pertenecer a la esencia misma de la hermenéutica el hecho de que ella tenga éxito sobre todo en particulares circunstancias históricas. Tal es la situación de la modernidad en general, que presupone en su base - desde el Renacimiento y la Reforma protestante- explícitas rupturas con la tradición y vistosos ocasos de certezas, derivante del colapso de determinadas visiones globales del mundo (desde el cristianismo universal del Medioevo hasta la filosofía absoluta del idealismo hegeliano). Tal es la situación de la civilización contemporánea, vuelta ahora un gigantesco sistema hermenéutico". ${ }^{46} \mathrm{El}$ "sistema" hermenéutico, empero, es un sistema impropio; es, más que otra cosa, una metodología que contempla la posibilidad de variar y adaptarse a las situaciones textuales y contextuales del tiempo. El "sistema" hermenéutico, en efecto, no es siempre unívocamente explicitable, salvo en algunas de sus adquisiciones fundamentales, como la expresada en la presente ecuación: ser-lenguajeinterpretación. En este sentido, el ser se "autodevela" en el lenguaje y en la interpretación, no en cuanto puede ser pensado, sino en cuanto se manifiesta al hombre.

También los filósofos posmodernos rehuyen al sistema, pero sostienen algunos puntos semejantes, a pesar de las diversas formulaciones, que consienten comprender cuáles son las directivas generales de su concepción de la realidad, una realidad posmoderna, justamente, que se configura como "la incredulidad de las metanarraciones" ${ }^{47}$ En tal sentido, la antimetafísica explicitada en la desconfianza en los sistemas globales y unitarios, a partir de la "convicción" dogmática de la inexistencia de fundamentos últimos y unita-

sentido se puede hablar, por ejemplo, de ontología de la física, de ontología de la matemática, pero también, como ha surgido últimamente, de ontología del teléfono cecular (M. Ferraris 2005).

${ }^{46}$ G. Fornero - S. Tassinari 2002, vol. II, p. 1022.

${ }^{47}$ J.-F. Lyotard 1981, p. 5 
rios del saber y el actuar, se vuelve la base de un pseudo-sistema quebrantado en el cual se registra el definitivo ocaso de la idea de una historia orientada a un fin. Tal constatación, sin embargo, es expresada por Vattimo de modo dogmático, como si se tratase de una revelación: "no hay, no se cree ya que haya una línea escatológica, un camino hacia un fin". ${ }^{48}$ En esto consistiría el anuncio posmoderno.

Siempre en el ámbito del uso lingüístico de los términos, es necesario relevar que tanto entre los filósofos analíticos como entre los pensadores postheideggerianos, rechazan los términos fuertes utilizados en asersiones relevantes, como la afirmación según la cual, por ejemplo, "todo existe en la realidad tangible", porque estos términos (aquí por ejemplo, es un juego el término todo) resultan, a su parecer, epistemológicamente más débiles. Un aserto más débil, al contrario, en cuanto no tiene la pretensión de determinar en un modo único una cosa, admitiendo como base una pluralidad de posibilidades, resultaría, al contrario, lógicamente más fuerte. Con base en esta precisión, resultaría imposible confutar, por ejemplo, la siguiente afirmación: "algo existe". No especificando apriorísticamente ni la modalidad de existencia de este algo, ni el elemento cuantificador, decir simplemente que "algo existe”, como respuesta a la pregunta “¿qué cosa existe?”, constituye un punto de partida imprescindible aceptado prácticamente por toda ontología, sea que se cierre en la inmanencia, o bien que se abra a la trascendencia.

La pregunta ontológica fundamental "¿qué cosa existe?” y la consecuente asersión "existe algo", en efecto, quedan como elementos lógica y lingüísticamente ineliminables, pero también, obviamente, ontológicamente significativos. Esto es así porque, si no efectuamos la pregunta, no podemos siquiera iniciar una indagación ontológica que, explícita o implícitamente - de acuerdo con se admita - el hombre advierte la exigencia de que debe efectuarla. También la respuesta es ineliminable, y esto porque, como ha subrayado Qui$\mathrm{ne}^{49}$, no tendría sentido hablar de entidades inexistentes y porque, como ha puesto de relieve Hartmann ${ }^{50}$, la afirmaciónd del aliquid est está más allá de cualquier sistema filosófico.

El pensamiento, la palabra o un ente, en efecto, no son nada, sino algo (aliquid) y, por lo demás, algo que existe (est) en un determinado modo y que es demostrado en cuanto existente (ontología), pero también en la modalidad

\footnotetext{
${ }^{48}$ J.-F. Lyotard - G. Vattimo 1991, p. 17.

${ }^{49}$ W. V. O. Quine 1966, p. 3.

${ }^{50}$ Cfr. N. Hartmann 1935, p. 40.
} 
de su existencia, esto es, como existente (metafísica). En tal sentido, siguiendo la intuición de Meinong ${ }^{51}$, se podría incluso sostener que también los objetos no-existentes en la realidad tangible forman parte de la ontología, sobre la base del significado que poseen. Si digo, por ejemplo, "Pegaso", estoy seguro de su inexistencia en la realidad factual, pero el término "Pegaso" tiene un significado en el ámbito de la mitología griega y, gracias al significado de "caballo alado", existe en un cierto modo, si bien no es un objeto "existente" del que pueda tener una representación específica: el modo de existencia y el significado de un término poseen, entonces, un vínculo fuerte. En tal sentido, pues, se podrá decir que también un sueño tiene su propia realidad, es decir, una modalidad de existencia onírica, significativa para quien lo ha hecho. Es preciso notar, empero, que sin la presencia real de una persona, o sea, de un Yo consciente, todo esto no sería siquiera expresable. Sin un Yo no se podría siquiera enunciar y aplicar el principio de identidad o el principio de no contradicción, por lo que la existencia de un Yo concreto postula además el reconocimiento de un principio desde el cual se originan los susodichos principios, o sea, el rosminiano principio de cognición, por medio del cual es posible enunciar que "el objeto del pensamiento es el ser". ${ }^{52}$

Si bien es verdad que en el ámbito analítico está en acto una verdadera y propia revolución teorética que está reconsiderando, sobre un plano de formulación lógico-proposicional, algunas problemáticas concernientes a la metafísica clásica, y es igualmente verdad que en el ámbito de la nueva fisionomía que ha asumido la fenomenología francesa hay posiciones, como la de Marion, que no tienen temor en afirmar que todos nosotros somos "espontáneamente metafísicos" 53 , o la de Falque que sostiene superada la "superación" 54 de la metafísica, queda todavía abierta la cuestión fundamental acerca del significado de metafísica. Si el ámbito fenomenológico y analítico parecen hoy los más interesados por regresar a redescubrir el valor imprescindible de la "metafísica", sea desde un punto de vista histórico como teorético, esto significa que el parecer de muchos intérpretes, según los cuales la proyección heideggeriana se entendería casi como la última expresión plausible de la metafísica occidental, resulta cuando menos discutible, así como cualquier intento implícito o explícitamente post-metafísico.

${ }^{51}$ Cfr. A. Meinong 2003.

${ }^{52}$ A. Rosmini 2004, n. 567, p. 135.

${ }^{53}$ J.-L. Marion - É. Tardivel 2018, p. 38.

${ }^{54}$ E. Falque 2017, p. 186. 
Las críticas heideggerianas a un cierto tipo de metafísica, la clásica, sobre todo en su configuración aristotélico-tomista, no han impedido a algunos filósofos lanzar reservas no sólo en las confrontaciones de la opción heideggeriana, sino también en relación a la opción metafísica como tal, como ha buscado hacer Habermas. ${ }^{55} \mathrm{Nef}^{56}$, empero, recientemente ha subrayado a mi parecer de modo eficaz - cómo la conocida estructura onto-teo-lógica que Heidegger atribuiría a la metafísica en general no tendría ningún punto en la metafísica aristotélica, la cual, desde un punto de vista ontológico, resultaría conducir al pensamiento analítico contemporáneo a través de las amplias etapas significativas que pasan por Tomás de Aquino, Leibniz y Brentano, el célebre maestro de Husserl. Pero quien ha polemizado con Heidegger ha terminado por polemizar con los representantes de la metafísica en cuanto tal. Escribe Berti: "Carnap por metafísica entiende la filosofía de Heidegger, Heidegger por metafísica entiende la onto-teología de la tradición aristotélico-tomista, Habermas entiende la metafísica de la tradición platónico-neoplatónico-idealista, Vattimo entiende toda filosofía que pretenda una forma de objetividad y definitividad, que él representa como violencia" 57 , y sin embargo las referencias continúan siendo implícitamente platónicas ${ }^{58}$ y explícitamente aristotélicas ${ }^{59}$, y esto porque ambos modelos metafísicos, a pensar de sus diferencias, se vinculan por el hecho de ser expresiones de una

${ }^{55}$ Cfr. J. Habermas 1991.

${ }^{56}$ Cfr. F. Nef 2004, pp. 353-e54.

${ }^{57}$ E. Berti cit., p. 162.

${ }^{58}$ La metafísica platónica es una metafísica trascendentalista de la participación, esto es, una metafísica en la que el fundamento reside en un principio primero dotado de perfección por esencia, mientras las otras realidades poseen tal perfección derivadamente, porque participan de aquélla. El método de la metafísica platónica es axiomático y deductivo, en cuanto deduce los efectos a partir de las causas ( $c f r$. G. Reale $2003^{21}$ ). No hay que olvidar que la metodología típica de "seccionar la realidad" es, antes que nada, una herencia platónica ( $c f r$. Platón, cit., 265 C-273 D, pp. 571-578) que sólo últimamente los mismos filósofos analíticos están dispuestos a reconocer, sobre todo en el ámbito australiano (Cfr. D. M. Armstrong 2016).

${ }^{59}$ La metafísica aristotélica, en cambio, es una metafísica trascendentalista de la experiencia en cuanto, aun reconociendo que el fundamento de la realidad trasciende a la realidad misma, procede, desde un punto de vista metodológico, inductivamente, o sea, de los efectos a las causas ( $c f r$. G. Reale $1993^{5}$ ). Este tipo de procedimento metodológico, unido al hecho de que las primeras tres de las cuatro conocidas definiciones dadas por Aristóteles de la metafísica se refieren respectivamente a: l'etiologia, o sea, a la indagación de las causas y primeros principios ( $c f r$. Aristotele 1990, pp. 1127), la ontología, o sea, la indagación del ser en cuanto ser (cfr. Aristotele pp. 131-185; pp. 273-283; pp. 493-497) y la usiología, esto es, la indagación sobre la substancia (cfr. Aristotele pp. 287-539) - la cuarta definición es la que define la metafísica como una teología, porque investiga a Dios y la substancia suprasensible (cfr. Aristotele pp. 269-273; pp. 543-585) -, nos permiten comprender aquella explícita referencia aristotélica de gran parte de la filosofía analítica contemporánea. 
metafísica propia y legítima: ambas desarrollan una concepción que contempla toda la realidad, y ambas presentan el paso a la trascendencia, mientras que con Heidegger y los post-heideggerianos tal recorrido resulta más bien impracticable.

Como ha observado correctamente Mondin, en efecto, la posición heideggeriana es por sí misma muy ambigua: "Por una parte, parece tener un altísimo concepto de aquella forma de saber que suscita, domina y determina toda interrogante y toda valoración ${ }^{60}$; por la otra, su regreso a Parménides quiere ser una superación de la metafísica"61, porque Heidegger entrevé en la Idea platónica y en la substancia aristotélica sólo una degradación del ser a una de sus manifestaciones. Heidegger, que propone un nuevo recorrido de la filosofía para comenzar con los primeros filósofos, sobre todo Parménides, en cuanto inmunes — a su juicio- al olvido del ser del son culpables Platón y Aristóteles, termina por desaprobar la inmobilidad y la estaticidad del ser parmenídeo a favor de una concepción mutable y dinámica del ser que se revela en la historia.

Heidegger, en el curso del desarrollo de su pensamiento, sostiene que se debe introducir el concepto de diferencia ontológica entre ser y ente, olvidándose, como ha hecho notar agudamente Beierwaltes ${ }^{62}$, que tal distinción ya obraba en Proclo y Plotino. También Rosmini introduce la diferencia ontológica para explicar más propiamente la diferencia entre ser relativo y Ser absoluto, para que no se confunda lo contingente con lo absoluto, y para que no se confunda el ser intuido ${ }^{63}$ y abstracto con el ente, que no es sino "el ser con

${ }^{60}$ M. Heidegger 1979, p. 22.

${ }^{61}$ B. Mondin 1999, p. 68.

${ }^{62}$ Cfr. W. Beierwaltes 1991.

${ }^{63} \mathrm{El}$ ser es la primera cosa participada al hombre y se encuentra por naturaleza en todo ente finito. Esto significa que el hombre participa de aquel ser como ser intuido y abstracto, pero no en cuanto substancia o esencia del Ser subsistente ( $c f r$. A. Rosmini, cit., n. 1426, pp. 1486-1487) y es definido, en sentido general, como "el acto de todo ente y toda entidad" (A. Rosmini, cit., n. 211, p. 380). El ser puede ser considerado también como aquello que es intuido por el hombre, o sea, el ser indeterminado. Entendido de tal manera, tiene en sí una característica implícita, casi escondida, que tiene la facultad para manifestarse durante los sucesivos actos del conocer. En este ser intuido por el hombre están presentes de modo velado todos sus términos, unido a los cuales está en grado de hacer presente al pensamiento los conceptos concernientes a los entes. Este ser con sus agregados es llamado por Rosmini ser virtual: "Es el ser considerado en relación a su virtualidad. Si lo consideramos en relación a los entes y entidades actuales, los admite todavía la definición: el acto del ente y las entidades; pero la relación, en la cual la reflexión de la mente lo considera, es diversa" (A. Rosmini, cit., n. 214, pp. 381-382). Así como no existe ni puede existir algún ente o entidad sin que tenga el acto de ser, esto significao que el ser adquiere la noción de inicio tanto de todo ente como de toda entidad. Para significar el ser en esta relación, Rosmini utiliza el término ser inicial. Cuando el hombre, por medio 
su término". ${ }^{64}$ Se comprende, por ende, que regresar heideggerianamente ${ }^{65}$ al ser, al estudio del ser, a la problemática del ser, a la verdad del ser, aun distinguiéndolo del ente, significa, en último análisis, reducir la metafísica a la ontología, que es algo muy diverso de la tentativa por reconducir la metafísica a la ontología para que se configure como una Teosofía, es decir, en una ciencia que "trata de todo el ser" 66 , tanto en su posibilidad, como en su subsistencia.

Como demuestra Rosmini siguiendo la intuición de Cesare Baldinotti ${ }^{67}$, todo depende de qué concepción del ser y del ente que se quiera expresar: "si la Metafísica es la doctrina filosófica del ente real, ella no puede abarcar más que la rama de las ciencias Ontológicas que tratan del ente real tal como es [...]. Por tanto, no sin buena razón algunos toman la palabra Metafísica como sinónimo de Ontología"68, pero la ontología de la que habla Rosmini se distingue en universal y especial, y en el momento en que el razonamiento se pone a considerar no el ser como es concebido en la idea, "sino como debe subsistir en sí mismo, aunque el hombre no lo conciba así, entonces se abre la ciencia del Ser supremo y absoluto, del Ente de los Entes, es decir, se entra en la Teología"69, y así la ontología puede ser entendida también como una suerte de gran prefacio a la teología: es aquí que la apertura a todo el ser, a toda la verdad del ser, a toda la realidad del ser lleva a efectuar el paso hacia la trascendencia.

Esto explica cómo la ontología, si se entiende adecuadamente, no debe quedar encerrada en una suerte de recinto de los entes finitos, casi como pri-

\footnotetext{
de la abstracción, prescinde de todos los términos vinculados al ser intuido y lo considera por sí mismo, entonces se vuelven una pura entidad de razón y, para significarla, el filósofo roveretano usa el término ser abstracto. En conclusión, se puede afirmar que "El ser virtual, entonces, el ser incial y el ser abstracto preciso son tres significados que recibe el vocablo ser, el cual, siendo palabra que admite una definición indeterminada, los abarca a los tres, según que la mente lo observe en varias relaciones" (A. Rosmini, cit., n. 216, p. 382).

${ }^{64}$ A. Rosmini, cit., n. 218 , p. 384.

${ }^{65}$ De los dos recorridos proyectados por Heidegger, uno conduce a la nada, el otro a un panteísmo ontológico que no puede ser aceptado en el contexto de las metafísicas propias. El Heidegger de Ser y tiempo ( $c f r$. M. Heidegger $2000^{15}$ ) propone un recorrido esencialmente antropocéntrico que parte del ser-ahí para buscar alcanzar el ser, pero la analítica existencial conduce a la nada. El Heidegger de los escritos sucesivos ( $c f r$. M. Heidegger, Introduzione alla metafisica, al cuidado de G. Vattimo, Mursia, Milán 2014; In cammino verso il linguaggio, al cuidado de A. Caracciolo, Mursia, Milán 2014) propone un recorrido contrario, esencialmente ontocéntrico, que parte del ser para alcanzar el ser-ahí.

${ }^{66}$ A. Rosmini, cit., n. 98 , p. 304.

${ }^{67}$ Cfr. C. Baldinotti 1817.

${ }^{68}$ A. Rosmini 1988, n. 18, p. 26.

${ }^{69}$ A. Rosmini, cit., n. 103 , p. 306.
} 
sionera de sí misma, sino que explica además cómo es discutible una posicíón que contemple la imposibilidad de interacción entre una ontología y una moral. Si, por ejemplo, se reduce la ontología a la lógica, como hacen algunos fenomenólogos y la mayor parte de los analíticos, o, siguiendo a Hartmann ${ }^{70}$, si se sostiene que la ontología debe ser propiamente el fundamento de todo saber, en cuanto estudia al ser en cuanto tal, mientras la metafísica debe ser entendida como el ámbito de lo incognoscible y lo irracional, entonces tal concepción resulta indudablemente difícil: la reconducción de la metafísica a la ontología tiene sentido sólo si de la ontología se tiene una concepción no exclusionista, es decir, abierta a todo el ser, a toda la verdad, la realidad y moralidad del ser, pero para que esto suceda no es posible reducir la metafísica a la suma de los problemas abiertos e insolubles.

Siguiendo la teoresis rosminiana, que no reduce la ontología a la lógica y la metafísica al ámbito de lo irracional, se comprende que la persona concreta (no la categoría abstracta de persona), el yo que es conciencia y libertad, tiene la posibilidad de "llegar a una Teoría del ser en toda la amplitud de su posibilidad" 71 , descubriendo que "el ser tiene esencialmente tres actos que son la objetividad, la subjetividad y la moralidad, al que da el nombre de formas y categorías, y que en cada una de ellas el ser es idéntico"72. Esta "relación de la Metafísica con las ciencias Deontológicas es sobremanera íntima, ya que la doctrina que demuestra cuál es el ente, es el fundamento de aquella que indaga cuál debe ser el ente para que sea perfecto"73. Ya en la Teodicea ${ }^{74}$, en efecto, Rosmini había mostrado el circuito característico que impele a una ontología a volverse una metafísica completa y en la Psicología había remachado con claridad que el ente real, que es el objeto de la ontología, "no está completo si no tiene en su propio seno la forma moral, que complementa y perfecciona al ente". 75

Tomar a examen la totalidad del ser, empero, no significa limitarse a sostener que la ontología deba tener por objeto sólo la realidad, entendida como el conjunto de sus elementos concretos, por el simple motivo de que "la sola

\footnotetext{
${ }^{70} C f$ r. N. Hartmann 1935. Para una confrontación crítica entre Hartmann y Rosmini en el ámbito ontológico, cfr. S. F. Tadini 2007, I, pp. 69-80.

${ }^{71}$ A. Rosmini, cit., n. 103, p. 305.

${ }^{72}$ Ibid.

${ }^{73}$ A. Rosmini, cit., n. 19, p. 26

${ }^{74}$ Cfr. A. Rosmini 1977, nn., pp. 384-394

${ }^{75}$ A. Rosmini, cit., n. 19, pp. 26-27.
} 
realidad necesita de la idea; sin ella, no es objeto de ciencia ni de cognición"”76, como Rosmini claramente ha demostrado en el Nuevo ensayo ${ }^{77}$ y en el Sistema filosófico ${ }^{78}$. La realidad, en efecto, no es todavía ente, sino que "está en camino a ser ente; tampoco contiene ella razón alguna de sí misma"79, porque, como ha Rosmini demostrado en los Principios de la ciencia moral ${ }^{80}$, "la razón de las cosas es siempre una idea" ${ }^{81}$ Esto significa que todos los elementos de la realidad, aquello que con lenguaje común denominamos "cosas reales", se vuelven objeto del saber sólo cuando se aprehenden "en relación a la idea, por la idea y en la idea". ${ }^{82}$ En tal sentido, la "doctrina filosófica del ente real" 83 expresa racionalmente una determinada y fundamental concepción de la realidad en la medida en que ella es estudiada por las cuatro ciencias ontológicas: la psicología, la cosmología, la ontología y la teología natural, de las cuales, las últimas tres, constituyen la Teosofía, que es "propiamente la filosofía progresiva; la especulación por excelencia, el sistema" ${ }^{84}$ Pero, ¿cómo podrá definirse este sistema a la luz de una interpretación en clave ontológica? Thomas Davidson, que considera la filosofía rosminiana como "la más auténtica de todas las filosofías cristianas" 85 y que sostiene haya superado las aporías positivistas e idealistas de su tiempo, lo ha definido al mismo tiempo "Idealismo Objetivo, Realismo Subjetivo, Moralismo Absoluto". ${ }^{86}$

\section{Salir de la marginalidad: una perspectiva histórico-teorético-performativa}

Se nos podría cuestionar, en este punto, por qué motivos una metafísica tan avanzada, como es la rosminiana, ha quedado en los márgenes del debate filosófico contemporáneo. Como ya se ha demostrado en otro lado ${ }^{87}$, en el siglo XIX la filosofía rosminiana era conocida sobre todo en Italia, pero también en España, Sudamérica, Alemania, Francia, Inglaterra, Estados Unidos,

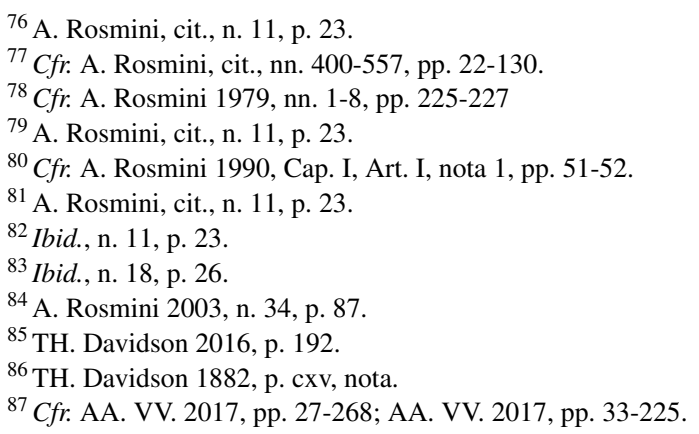


Rusia y en los países escandinavos, pero más allá de algunos estimadores, no parece que haya logrado generar, salvo en algunos ambientes extra-académicos, aquella renovación metafísica que habría garantizado una segura mejora del hombre fuera y dentro de la dimensión puramente confesional del pensamiento católico. Ciertamente de poco han servido las disputas neotomistas, abiertamente críticas del pensamiento rosminiano, y todavía menos la situación histórico-cultural, en la que estaban triunfado las filosofías cientificistas.

El rosminianismo filosófico se ha desarrollado teoréticamente en diversas direcciones, a veces asomables una en la otra, pero comoquiera bastante definibles como perspectiva reconstructivo-expositiva ${ }^{88}$, hermenéutico-dialógi$c a^{89}$ y, en parte, crítico-performativa. ${ }^{90}$ Es en esta última dirección que el pensamiento rosminiano podría ser repuesto hoy, sin descuidar, naturalmente, los resultados teoréticos ganados en el curso del tiempo por las perspectivas precedentes, no siendo la última la inaugurada por Michele Federico Sciacca

${ }^{88}$ Este filón ha asumidos dos direcciones antitéticas: a) la apologética, en la que el pensamiento rosminiano se defendía por su inequívoco valor, tanto por los rosminianos mismos ( $c f r$. G. Calza - P. Perez 1915), como por estudiosos del pensamiento del filósofo roveretano ( $f r$. L. M. Billia 1889); b) la polémica, por medio de la cual la reconstrucción y la reexposición del pensamiento rosminiano eran funcionales y propedéuticos a la formulación de una crítica del sistema mismo y sus contenidos. Esta dirección ha caracterizado al neotomismo del siglo XIX como reacción al rosminianismo (cfr. G. M. Cornoldi 1881; I. Mancini 1955, pp. 164-229).

${ }^{89}$ Este filón ha asumido varias formas, entre las cuales al menos es preciso recordar la opción gentiliana, la sciacchiana e la priniana. La primera, surgida en el contexto del actualismo de Giovanni Gentile ( $c f r$. G. Gentile 1955; Genesi e struttura della società, Sansoni, Firenze 1945) y su escuela, buscaba demostrar el valor imprescindible del aporte gnoseológico, pedagógico y moral del pensamiento rosminiano para el renacimiento de la filosofía italiana; la segunda, formulada por Michele Federico Sciacca ( $c f r$. M. F. Sciacca 1958) y proseguida por sus discípulos, proponía una recuperación del pensamiento rosminiano como una auténtica filosofía de la integralidad; la tercera, desarrollada por Pietro Prini, tendía a presentar un Rosmini con coloraciones existencialistas ( fr. P. Prini 1999 ${ }^{3}$ ).

${ }^{90}$ Este filón ha sido inaugurado por Giuseppe Buroni ( $c f r$. G. Buroni 1877); ha sido desarrolado, sólo en parte, por Thomas Davidson ( $c f r$. TH. Davidson 1882), pero ha sido reforzado por Vincenzo La Via ( $c f r$. V. La Via 1966), el cual, proveniente de la escuela actualista gentiliana, había propuesto una rigorización de los elementos terminológicos de la teoresis rosminiana en sentido crítico, cuyos resultados han emergido en las varias contribuciones de la revista Teoresi. Ahí donde la línea sciacchiana partía de un presupuesto metafísico para reafirmar una metafísica, la línea laviana partía de un presupuesto crítico para alcanzar una metafísica. Interesante notar cómo el Giornale di metafisica, fundado y dirigido por Sciacca en 1946, ya por el nombre parece colocarse en un contexto específico, es decir, el de la metafísica clásica, mientras que el nombre Teoresi, fundada y dirigida por La Via también en 1946, ya desde el título aparece menos conforme con un determinado ámbito metafísico. Resulta igualmente interesante lo que afirma Sciacca, en relación al pasaje efectuado por él, junto a La Via, del actualismo gentiliano a la metafísica rosminiana: "sobre Gentile, de quien La Via y yo, además de la del roveretano, hemos recibido, como discípulos, la lección, incluso si, precisamente por la fuerza del Rosmini filósofo, la hemos repensado y visto hasta el punto de que, si podemos llamarnos rosminianos desde nuestro personal punto de vista, no podemos llamarnos, en nada, gentilianos" (M. F. Sciacca 1973, p. 433). 
y por la escuela. En tal sentido se podría expresar su más que legítimo espíritu performativo, no todavía explicitado, a mi parecer, de modo adecuado. Ciertamente, hoy no sería aceptada una suerte de escolástica rosminiana para proponerse como servil repetición de una filosofía históricamente desarrollada y ligada a un preciso contexto cultural, pero tampoco Rosmini lo habría querido. No hay que olvidar que el sistema de la verdad propuesto por Rosmini es un sistema abierto que, a partir de principios fundamentales, puede progresar en dirección a una siempre mayor clarificación de la verdad. Por eso, una simple reproposición del pensamiento rosminiano sería vista, en la mejor de las hipótesis, simplemente como una operación de historia de la metafísica, ciertamente meritoria, pero "marginal" en un contexto contemporáneo, donde el "mercado de las ideas" parece haber elegido otros caminos que escapan de las visiones reconstructivas-sistemáticas-completas. Esto no significa que la dirección actual sea la mejor - personalmente tengo ciertas reservas- y no significa ni siquiera que sea obligatorio adecuar los contenidos a las modas filosóficas del momento. Lo que sostengo que es posible, en cambio, es buscar proponer contenidos válidos del pensamiento rosminiano en el contexto de metodologías que parecen hoy haber manifestado un claro interés por la metafísica, respecto a un pasado muy reciente.

Por esta razón sostengo que es posible imaginar, después del renacimiento del interés por la metafísica, una recuperación en sentido ontoprismático ${ }^{91}$ - es decir, capaz de contemplar, en la pluralidad de las perspectivas, las caracterizaciones verídicas de la realidad en todo lo que se ofrece al hombrede la sistematicidad rosminiana. Sostengo que una vez que nos hayamos dado cuenta de que la misma propuesta de Rosmini no es una repetición de su propia filosofía, sino la del progreso de las ideas a la luz de la verdad vuelta sistema, de la que él mismo ha sido uno de los mayores exponentes, será posible responder afirmativamente incluso a la pregunta sobre la posibilidad o no de progresar en metafísica. ${ }^{92}$ En tal sentido, el pensamiento rosminiano, si se le percibe honestamente, puede contribuir a revelar teoréticamente soluciones plausibles para problemas siempre actuales y considerados determinantes, sobre todo por las hodiernas "metafísicas" y ontologías dominantes ${ }^{93}$, sin olvidar que la metafísica de Rosmini es una Teosofía, o sea, una elaboración

${ }^{91}$ Cfr. S. F. Tadini 2016, pp. 59-75.

${ }^{92}$ Cfr. A. Marmadoro - E. Mayr 2017, p. 139.

${ }^{93}$ Con el término "ontologías dominantes" entiendo indicar las diversas teorías ontológicas que, en el debate contemporáneo, se han configurado sobre todo en el seno de la filosofía analítica postwittgensteiniana, $c f r$. S. F. Tadini 2017, pp. 141-161. 
sistemática de una concepción de la realidad abierta a la verdad, en donde el único presupuesto es, justamente, que la verdad exista. Esta metafísica de la trascendencia, abierta a la dimensión sapiencial (cristianamente entendida), capaz de ser al mismo tiempo meta-platónica y meta-aristotélica, combate el cientificismo, sosteniendo el valor de la ciencia ${ }^{94}$, y combate el subjetivismo, revalorando al sujeto por excelencia de la pregunta metafísica, a saber, la persona $^{95}$ (la parte más elevada del hombre ${ }^{96}$ ), la cual está llamada responsablemente a reconocer sapiencialmente al ser, a indagar según la verdad y a vivir moralmente lo que es esencialmente la auténtica libertad.

\section{Bibliografía}

AA.VV., (1986-1994), Vocabolario della lingua italiana, 5 voll., Istituto della Enciclopedia Italiana, Roma.

Abécassis, E., (2004), Piccola metafisica dell'omicidio, Il Nuovo Melangolo, Genova. Agostino D'Ippona, (1968), Commento al Vangelo di Giovanni, a cura di A. Vita, E. Gandolfo e V. Tarulli, (XXIV), Città Nuova, Roma.

—, (1821), Del modo di catechizzare gli idioti, traduzione di A. Rosmini, Giuseppe Battaggia, Venezia.

Antunes, A.L., (2014), In culo al mondo, Feltrinelli, Milano.

Aristotele, (1990), Metafisica, a cura di G. Reale, Vita e Pensiero, Milano.

Armstrong, D.A., (2016), Che cos'è la metafisica, Carocci, Roma.

Bachelard, G., (2016), Metafisica della matematica, Castelvecchi, Roma.

Bahr, I., (2007), Stupida puttana. I miei viaggi in Asia da pseudovergine ventenne, Einaudi, Torino.

Beierwaltes, W., (1991), Pensare l'Uno, Vita e Pensiero, Milano.

Baldinotti, C., (1817), Tentamina metaphysica, Tip. del Seminario, Padova.

Berti, E., (2017), Introduzione alla metafisica, Utet - De Agostini, Novara.

Billia, L.M., (1889), Quaranta Proposizioni attribuite ad Antonio Rosmini coi testi originali dell'Autore e con altri dello stesso che ne compiono il senso, Ulrico Hoepli, Milano.

Bucelli, V., (2018), Nell'occhio del pettirosso. Come la fisica quantistica ha cambiato la visione filosofica del mondo, Mimesis, Milano-Udine.

${ }^{94}$ Rosmini sostiene que la filosofía deb ser "sólida base para las ciencias" (A. Rosmini 1979, n. 9, p. 28) y debe tener en cuenta los resultados de las ciencias particulares a fin de penetrar siempre más en el mundo empírico que nos circunda y en el que estamos inmersos, anticipando en gran medida intuiciones y adquisiciones de la epistemología contemporánea, que no parece espantarse con admitir la necesidad de la metafísica ( $c f r$. V. Bucelli 2018, en particular el cap. XV dedicado a la Metafísica cuántica, pp. 105-112).

${ }^{95}$ Cfr. S. F. Tadini 2015, pp. 89-112.

${ }^{96}$ Escribe Rosmini que "El principio personal del hombre no es todo el hombre; este principio no es más que el mejor elemento del hombre, la cima más alta de la naturaleza humana" (A. Rosmini 1997, p. 137). 
Buroni, G., (1877), Dell'essere e del conoscere. Studii su Parmenide, Platone e Rosmini, G.B. Paravia, e Comp., Torino.

Busi, A., (2002), Cazzi e canguri. Pochissimi i canguri, Mondadori, Milano.

Callini, D., (2008), Arcani al lavoro. Metafisica della vita organizzativa, Franco Angeli, Milano.

Calza, G. y Perez, P., (1915), Esposizione ragionata della filosofia di Antonio Rosmini con uno sguardo al luogo ch'ella tiene fra l'antica scienza e la nuova, 3 voll., voll. I, II, Bertolotti, Intra 1878-1879, vol. III, Boriotti-Majocchi-Zolla, Voghera.

Carnap, R., (1969), Il superamento della metafisica mediante l'analisi logica del linguaggio, in AA. VV., Il neoempirismo, a cura di A. Pasquinelli, Utet, Torino 1995, pp. 504-532.

Carulli, A., (2017), Metafisica delle mestruazioni, Il Nuovo Melangolo, Genova.

Casalino, G., (2003), Il nome segreto di Roma. Metafisica della romanità, Edizioni Mediterranee, Roma.

Coccia, E., (2018), La vita delle piante. Metafisica della mescolanza, Il Mulino, Bologna.

Cornoldi, G.M., (1881), Il Rosminianesimo sintesi dell'ontologismo e del panteismo, Tip. e Libreria di Roma, Roma.

Corradetti, D., (2008), Metafisica del numero. Vol. 1: Elementi di simbolismo matematico, Il Pavone, Messina.

Damonte, M., (2011), Rosmini e la filosofia analitica della religione, «Rivista rosminiana», 2011, f. I, pp. 11-28.

— , (2018), Un'altra teologia naturale. Rosmini, filosofia anglofona e filosofia analitica, in S.F. Tadini (a cura di), Rosminianesimo filosofico, Anno II, 2018, Mimesis, Milano-Udine 2018, pp. 245-276.

—, (2011), Una nuova teologia naturale. La proposta degli epistemologi riformati e dei tomisti wittgensteiniani, Carocci, Roma.

Davidson, TH., (2016), Rosmini's Philosophy, in S.F. Tadini, Thomas Davidson e la filosofia rosminiana, Edizioni Rosminiane, Stresa.

—, (1882), The Philosophical System of Antonio Rosmini-Serbati, Kegan Paul, Trench \& Co., London.

De Sutter, L., (2017), Metafisica della puttana, Giometti \& Antonello, Macerata.

Di Pace, F., (2018), Bambini e metafisica. Dio, il destino e Mandrake. Quando i piccoli ragionano dell'Assoluto, Fefè, Roma.

Evola, J., (2001), Metafisica della guerra, Edizioni di AR, Padova.

—, (1993), Metafisica del sesso, Edizioni Mediterranee, Roma.

Falque, E., (2017), Passare il Rubicone. Alle frontiere della filosofia e della teologia, Morcelliana, Brescia.

Ferraris, M., (2005), Dove sei? Ontologia del telefonino, Bompiani, Milano.

- (2008), (a cura di), Storia dell'ontologia, Bompiani, Milano.

Fornero, G. y Tassinari, S., (2002), Le filosofie del Novecento, 2 voll., Bruno Mondadori, Milano.

Gentile, G., (1945), Genesi e struttura della società, Sansoni, Firenze. 
—, (1955), Rosmini e Gioberti, Saggio storico sulla filosofia italiana del Risorgimento, Sansoni, Firenze.

Giannini, G., (2007), Metafisica del conflitto, Il Nuovo Melangolo, Genova.

Gilson, E., (1952), Being and some Philosophers, Pontifical Institute of Mediaeval Studies, Toronto.

Givone, S., (2012), Metafisica della peste. Colpa e destino, Einaudi, Torino.

Habermas, J., (1991), Pensiero postmetafisico, a cura di M. Calloni, Laterza, Bari.

Hartmann, N., (1935), Zur Grundlegung der Ontologie, Walter de Gruyter, Berlin .

Hegel, G.W.F., (1967), Enciclopedia delle scienze filosofiche in compendio, a cura di N. Merker, 2 voll., Laterza, Bari.

—, (2008), Scienza della logica, a cura di C. Cesa, 2 voll., Laterza, Roma-Bari. Heidegger, M., $\left(2000^{15}\right)$, Essere e tempo, a cura di P. Chiodi, Longanesi, Milano.

—, (2014), In cammino verso il linguaggio, a cura di A. Caracciolo, Mursia, Milano.

—, (2014), Introduzione alla metafisica, a cura di G. Vattimo, Mursia, Milano.

Heim, M., (2015), Metafisica della realtà virtuale, Guida, Napoli.

Husserl, E., (2002), Idee per una fenomenologia pura e per una filosofia fenomenologica, a cura di V. Costa e E. Filippini, Einaudi, Torino.

—, (1970), Meditazioni cartesiane, a cura di F. Costa, Bompiani, Milano.

—, (1968), Ricerche logiche, a cura di G. Piana, Il Saggiatore, Milano.

Incampo, A., (2010), Metafisica del processo. Idee per una critica della ragione giuridica, Cacucci, Bari.

Joad, C.E.M., (1951), A Critique of Logical positivism, University of Chicago Press, Chicago.

La Via, V., (1966), La restaurazione rosminiana della filosofia, Edizioni SPES, Milazzo.

Lenti, M., (2012), La metafisica di Harry Potter, Camelozampa, Monselice.

Locke, J., (2012), Saggio sull'intelletto umano, a cura di V. Cicero e M. G. D’ Amico, Bompiani, Milano.

Lyotard, J.-F., (1981), La condizione postmoderna, Feltrinelli, Milano.

Lyotard, J.-F. y VATTIMO, G., (1991), Noi, melanconici postmoderni, «La Stampa», 14 maggio 1991, p. 17.

Mancini, I., (1955), Il problema metafisico nello sviluppo del pensiero rosminiano, in AA.VV., Antonio Rosmini nel centenario della morte, Vita e Pensiero, Milano 1955, pp. 164-229.

Marion, J.-L., (2018), Dio e l'ambivalenza dell'essere, in J.-L- Marion y É. Tardivel, Fenomenologia del dono, a cura di C. Brentari, Morcelliana, Brescia 2018, p. 38.

Marmadoro, A. y Mayr, E., (2017), Breve introduzione alla metafisica, Carocci, Roma. Meinong, A., (2003), Teoria dell'oggetto, a cura di E. Coccia, Quodlibet, Macerata.

Melendo, G.T.I., (2005), Metafisica del concreto. I rapporti tra filosofia e vita, Leonardo da Vinci, Roma.

Micheletti, M., (2002), Filosofia analitica della religione. Un'introduzione storica, Morcelliana, Brescia. 
Mina Di Sospiro, G., (2016), Metafisica del ping-pong. Un'introduzione alla filosofia perenne, Ponte alle Grazie, Milano.

Mondin, B., (1999), Manuale di filosofia sistematica. Ontologia e metafisica, ESD, Bologna.

, (1998), Storia della metafisica, 3 voll., ESD, Bologna.

Nef, F., (2004), Qu'est-ce que la métaphysique, Gallimard, Paris.

Nietzsche, F., (1990), Frammenti postumi, 1885-1887, in Opere complete, a cura di G. Colli e M. Montinari, vol. 8/1, Adelphi, Milano.

Nothomb, A., (2016), Metafisica dei tubi, voland, Roma.

Ortoli, S. y Pharabod, J.-P., (2013), Metafisica quantistica. I nuovi misteri dello spazio e del tempo, Castelvecchi, Roma.

Platone, (2000), Cratilo, in Tutti gli scritti, a cura di G. Reale, Bompiani, Milano.

-, (2000), Epinomide, in Tutti gli scritti, a cura di G. Reale, Bompiani, Milano.

-, (2000), Fedone, in Tutti gli scritti, a cura di G. Reale, Bompiani, Milano.

-, (2000), Fedro, in Tutti gli scritti, a cura di G. Reale, Bompiani, Milano.

—, (2000), Filebo, in Tutti gli scritti, a cura di G. Reale, Bompiani, Milano.

—, (2000), Menone, in Tutti gli scritti, a cura di G. Reale, Bompiani, Milano.

—, (2000), Politico, in Tutti gli scritti, a cura di G. Reale, Bompiani, Milano.

—, (2000), Repubblica, in Tutti gli scritti, a cura di G. Reale, Bompiani, Milano.

-, (2000), Sofista, in Tutti gli scritti, a cura di G. Reale, Bompiani, Milano.

Prini, P., $\left(1999^{3}\right)$, Rosmini postumo, Edizioni Rosminiane Sodalitas, Stresa.

Putnam, H., $\left(2004^{3}\right)$, Introduzione. La filosofia del linguaggio e il resto della filosofia, in Mente, linguaggio e realtà, Adelphi, Milano 2004 ${ }^{3}$, p. 21.

Quine, W.V.O., (1966), Su ciò che vi è, in Il problema del significato, Ubaldini, Roma 1966, p. 3.

Reale, G., $\left(1993^{5}\right)$, Il concetto di filosofia prima e l'unità della Metafisica di Aristotele, Vita e Pensiero, Milano.

- $\left(2003^{21}\right)$, Per una nuova interpretazione di Platone, Vita e Pensiero, Milano.

Renik, S., (2015), Vedo cambiare il tempo. Metafisica del macchinismo e le passioni dell'anima, Mimesis, Milano-Udine.

Rinaldi, R., (2017), La metafisica dello sterco, Pluriversum, Ferrara.

Ritter, J., (2000), Metafisica e politica, Marietti, Bologna.

Rosmini, A., (1979), Degli studi dell'Autore, in Introduzione alla filosofia, a cura di P.P. Ottonello, (2), Città Nuova, Roma.

—, (1997), Filosofia della politica, a cura di M. d'Addio, (30), Città Nuova, Roma.

—, (1984), Logica, a cura di V. Sala, (8), Città Nuova, Roma.

—, (2005), Nuovo Saggio sull'origine delle idee, a cura di G. Messina, (3-5), Città Nuova, Roma.

-, (1988), Prefazione alle opere metafisiche, in Psicologia, a cura di V. Sala, (9), Città Nuova, Roma.

-, (2003), Preliminare alle opere ideologiche, in Nuovo Saggio sull'origine delle idee, a cura di G. Messina, (3), Città Nuova, Roma. 
— , (1990), Principi della scienza morale, a cura di U. Muratore, (23), Città Nuova, Roma.

, (1979), Sistema filosofico, in Introduzione alla filosofia, a cura di P.P. Ottonello, Città Nuova, Roma.

—_, (1977), Teodicea, a cura di U. Muratore, (22), Città Nuova, Roma.

v (2011), Teosofia, a cura di S.F. Tadini, Bompiani, Milano.

Sartre, J.-P., (2014), L'essere e il nulla, Il Saggiatore, Milano.

Scansani, S., (2007), Metafisica del tortello. Storia, filosofia, ricette della pasta ripiena, Tre Lune, Mantova.

Sciacca, M.F., (1958), Interpretazioni rosminiane, Marzorati, Milano.

—, (1973), Figure e problemi del pensiero contemporaneo, Marzorati, Milano.

Simmel, G., (2018), Metafisica della morte e altri scritti, SE, Milano.

Sombart, W., (1994²), Metafisica del capitalismo, Edizioni di AR, Padova.

Stirling, J.H., (1865), The Secret of Hegel: Being the Hegelian System in Origin, Principle, Form and Matter, 2 voll., Longman, Roberts \& Green, London.

Strawson, P.F., (1967), Construction and Analysis, in AA. VV., The Revolution in Philosophy, Macmillan, London 1967, p. 118.

Sutton, R.I., (2007) Il metodo antistronzi, Elliot, Roma.

Tadini, S.F., (2019), (a cura di), La filosofia dopo le "filosofie". La sfida rosminiana alla contemporaneità, Mimesis, Milano-Udine 2019, pp. 99-129.

—, (2007), Hartmann e Rosmini: due prospettive ontologiche a confronto, in «Rivista rosminiana», 2007, I, pp. 69-80.

—, (2015), Il problema di Dio nella metafisica rosminiana, Vita e Pensiero, Milano.

Tadini, S.F., (2015), La dimensión metafísico-teológica de la persona: la perspectiva rosminiana, in J. Buganza (a cura di), Cinco perspectivas actuales de antropología filosófica, Conaculta e Ivec, Xalapa (Mexico) 2015, pp. 89-112.

—, (2012), La Teosofia di Rosmini. Invito alla lettura, Edizioni Rosminiane, Stresa.

—, (2017), (a cura di), Rosminianesimo filosofico, Anno I, 2017, Mimesis, MilanoUdine.

—_, (2017), (a cura di), Rosminianesimo filosofico, Anno II, 2018, Mimesis, MilanoUdine.

—-, (2016), Rosmini e la nuova metafisica ontoprismatica: un dialogo possibile con l'ontologia analitica, in F. Bellelli y E. Pili (a cura di), Ontologia, fenomenologia e nuovo umanesimo. Rosmini ri-generativo, Città Nuova, Roma 2016, pp. 59-75.

- (2017), Teologia naturale rosminiana ed epistemologia riformata: le premesse per un possibile "dialogo ideale”, in F. Bellelli (a cura di), Rosminianesimo teologico. Il divino nell'uomo e l'umano nella Rivelazione, Mimesis, Milano-Udine 2017, pp. 65-107.

—, (2017), Teosofia rosminiana e ontologie dominanti. Per un pluralismo costruttivo, in G. Picenardi (a cura di), I semi del Verbo nel pluralismo religioso, teologico e filosofico, Edizioni Rosminiane, Stresa 2017, pp. 141-161.

Unger, E., (2008), Politica e metafisica. Tentativi filosofici in politica, Cronopio, Napoli. 
Urmson, J.O., (1974), L'analisi filosofica. Origini e sviluppi della filosofia analitica, Mursia, Milano.

Varzi, A., (2008), Introduzione, in AA. VV., Metafisica. Classici contemporanei, Laterza, Roma-Bari.

—, (2008), (a cura di), Metafisica. Classici contemporanei, Laterza, Roma-Bari.

Vattimo, G. y Rovatti, P.A., (2010), (a cura di), Il pensiero debole, a cura di, Feltrinelli, Milano.

Wisdom, J., (1938), Metaphysics and Verification, «Mind», 1938, 47, p. 454.

Wittgenstein, L., (1998), Tractatus logico-philosophicus, a cura di A.G. Conte, Einaudi, Torino.

Zangwill, N., (2011), La metafisica della bellezza, Marinotti, Milano. 